\title{
Crisis económica, cambio tecnológico y comercio exterior de México
}

\author{
José Luis Estrada López*
}

\begin{abstract}
This paper analyzes the implications of the economic crisis in the United Sates, for the reconsideration of the Mexican development strategy, especially in what has to do with Mexico's integration into the world economy. The situation of the Mexican economy is characterized by a long-term crisis on top of which the current economic turmoil is set. The former crisis manifests itself in serious drawbacks in terms of growth of per capita income, formal employment and productivity, as well as in the persistence of poverty and migration to the United States and into informal activities.

The nature and the magnitude of the current crisis, as well as the change that has made the Democrats, the dominant party in the White House and the Us Congress, make possible to think that the economic and political period, labeled as "neoliberal", has come to an end in 2008, and that a new period of less ideological extremism, and more rationality in the policy making arises. In this paper a thesis is uphold that the main drawback of the Mexican strategy is what the strategy lacked, although also discusses the no less serious flaws of what was done, and how it was implemented, specially in reference to the swift trade and capital account liberalization and the NAFTA negotiations.
\end{abstract}

Key words: Mexico, trade, development, crisis, NAFTA.

Number of classification: JEL: F13.

\begin{abstract}
RESUMEN
Este trabajo retoma la controversia de largo plazo entre aquellos enfoques que resaltan las bondades del sistema de mercado, libre de interferencias de gobierno, y los que, por el contrario, destacan la propensión a reproducir y/o incrementar las inequidades cuando el sistema capitalista se deja a su libre accionar. Se exploran las implicaciones de este debate, en el contexto actual de las revoluciones tecnológicas de la información, las comunicaciones y el Internet, así como la crisis mayor en la que ha desembocado el auge financiero en el mundo, para reconsiderar la estrategia mexicana de desarrollo. Las condiciones para esta reconsideración son la crisis de contagio que sufre el país, pero también lo que se puede considerar como una crisis de larga duración por el insuficiente crecimiento económico, de la productividad y los ingresos familiares. Como la crisis actual se acompaña con un cambio político en Estados Unidos, se abre la posibilidad de trascender el período de predominio conservador en este país, y de reestablecer un balance razonable entre mercado y políticas públicas. En la última parte se analizan varias condiciones que se consideran necesarias para que la participación pública sea eficaz y se eviten los errores en que se ha incurrido en pasadas experiencias de intervenciones gubernamentales en el país.
\end{abstract}

Palabras clave: México, comercio, desarrollo, crisis, TLCAN. Número de clasificación: JEL: F13.

* Doctor en Economía por The New School for Social Research, Nueva York. Profesor en el Departamento de Economía de la Universidad Autónoma Metropolitana-Iztapalapa. 


\section{INTRODUCCIÓN}

El propósito de este trabajo es analizar las implicaciones de la crisis económica en Estados Unidos y el reciente cambio político, para reconsiderar la estrategia mexicana de desarrollo, en especial en lo que tiene que ver con la política comercial y su inserción en la economía mundial. Este estudio se ubica dentro de la controversia entre los que, por un lado, defienden las bondades del mercado (libre de intervenciones de gobierno) y los que, por el otro, destacan la necesidad o conveniencia de buscar (y lograr) combinaciones adecuadas de políticas públicas y mercados, en el caso de aquellas economías subdesarrolladas que buscan reducir su brecha con el mundo industrializado.

Esta controversia se ha vuelto muy relevante en la actualidad. Para empezar, la principal contradicción en materia de política económica durante la era iniciada por el gobierno de Ronald Reagan en 1982, se ha dado en torno a la intervención o no del gobierno en los asuntos de negocios. Durante este cuarto de siglo pasado llegó a predominar la ideología de libre mercado en Estados Unidos, tanto en la política como en la teoría. Sin embargo, con los desfavorables resultados en cuanto a la distribución del ingreso en este país y sobre todo por la gravedad de la crisis actual y el alto grado de incertidumbre que la rodea, se vuelve a poner en duda esta tesis que Hayek (1944) defendió con tanto éxito.

Hay que agregar que, dentro del proceso de globalización y cambio tecnológico, algunos países subdesarrollados se han beneficiado y sus economías han logrado crecer en forma tan dinámica que han reducido considerablemente sus niveles de pobreza y proporcionado bienestar material a sectores muy amplios de sus poblaciones; los casos de varias economías asiáticas, dentro de las cuales destacan recientemente China e India, ilustran que es posible lograr diversos tipos de combinaciones exitosas entre políticas públicas, empresas privadas y mercado. Por lo contrario, otras economías, aunque se han integrado a la economía global, no han corrido con tal suerte y se enfrentan al problema de superar multitud de males económicos y sociales; el caso más destacado es el de nuestro país.

La sección I se dedica al estudio de la crisis económica y el cambio político en Estados Unidos con el propósito de mostrar que se ha cerrado el ciclo económico-político durante el cual llegó a predominar la visión más radical respecto a las bondades del libre funcionamiento de los mercados, lo cual abre espacios para la participación activa del Estado en la búsqueda de solución de problemas estratégicos que rebasan el ámbito exclusivo del mercado. En la sección II se analiza el papel que pueden jugar las tecnologías de la información y la co- 
municación (TIC) en la formulación y puesta en práctica de una alternativa de crecimiento que trascienda los resultados obtenidos por la actual estrategia.

En la tercera sección se analiza la crisis de larga duración en México y sus manifestaciones en términos de insuficiencia en el crecimiento del PIB por habitante, en la productividad y en la generación de empleo. La cuarta sección analiza la estrategia comercial del país e indaga hasta qué punto se omitieron acciones que podrían haber sido necesarias para lograr un mejor desempeño económico. Asimismo, se examinan las posibles fallas en el diseño mismo de la apertura comercial y sus modalidades de implementación y negociación con el TLCAN. Al final se exploran dos grupos de propuestas alternativas de políticas o reformas.

\section{CRISIS ECONÓMICA Y CAMBIO POLÍTICO EN ESTADOS UNIDOS}

En esta sección me propongo mostrar que existen razones económicas y políticas para afirmar que se ha cerrado el ciclo económico durante el cual llegó a predominar la visión más radical de libre mercado. Por el cierre de este periodo se entiende que ya se ha vuelto insostenible la estrategia basada en el principio de que los mercados, especialmente los financieros, disponen de la capacidad de autorregularse cuando se les libera de la supervisión de las entidades gubernamentales o públicas. Históricamente, esta estrategia de libre mercado vino a sustituir la otra visión, de inspiración keynesiana, que confió en que la economía mixta, i.e., la combinación de los mercados con el manejo de las políticas fiscal y monetaria por parte del gobierno, evitaría los efectos negativos de los ciclos económicos típicos del capitalismo. Este periodo se corresponde de manera muy marcada con la recesión económica e inflacionaria de principios de los ochenta y termina con la crisis financiera de 2008; por el lado político, el inicio se da con la inauguración del gobierno de Ronald Reagan en 1982 y termina con el de George W. Bush en 2008. En cuanto al fenómeno de la globalización, que ha sido concomitante con esta orientación ideológica, cabe señalar que, dadas las fuerzas que lo han impulsado (tecnologías de la información y de la comunicación, relocalización de la producción), no es de esperar una reversión del mismo, aunque sí modificaciones en sus formas de regulación y supervisión.

Para sustentar lo anterior mostraré el desempeño macroeconómico de la economía de Estados Unidos, en términos del PIB por habitante y de las principales características de la distribución del ingreso, así como el desempeño financiero que termina con su propio colapso en 2008. También es importante resaltar 
que, a diferencia del gobierno de ocho años del demócrata Bill Clinton, durante el cual continuó el predominio del núcleo básico de reglas políticas neoliberales y el Congreso de Estados Unidos siguió dominado por los conservadores republicanos, en 2008 el triunfo demócrata fue abrumador y el electorado se enfrentó al derrumbe de las expectativas que se habían generado por dicha doctrina y el auge económico de los años recientes.

Durante este lapso de un poco más de un cuarto de siglo, la economía de Estados Unidos tuvo un desempeño regular en términos de crecimiento y estabilidad económica. Efectivamente, el PIB creció a una tasa promedio anual de $3.03 \%$ en comparación con una tasa de $3.8 \%$ durante el periodo previo, de 1950 a 1980. Como puede apreciarse en la figura 1, esta expansión se dio en medio de fuertes variaciones, siendo menos pronunciada la del último periodo: el coeficiente de variación (desviación estándar entre el promedio) es considerablemente menor en el último periodo, 0.56, que en el anterior, 1.4; si se toma la frecuencia trimestral, la diferencia es de entre 0.88 y 1.4 respectivamente. Éste es un rasgo interesante pues en el periodo anterior dominó la política de regulación del ciclo económico basada en los ajustes de tipo keynesiano, mientras que en el último periodo, por lo contrario, se impuso la política de no interferencia del gobierno en los asuntos de mercado, excepto en momentos de crisis, como los que

Figura 1. PIB de Estados Unidos, 1930-2007

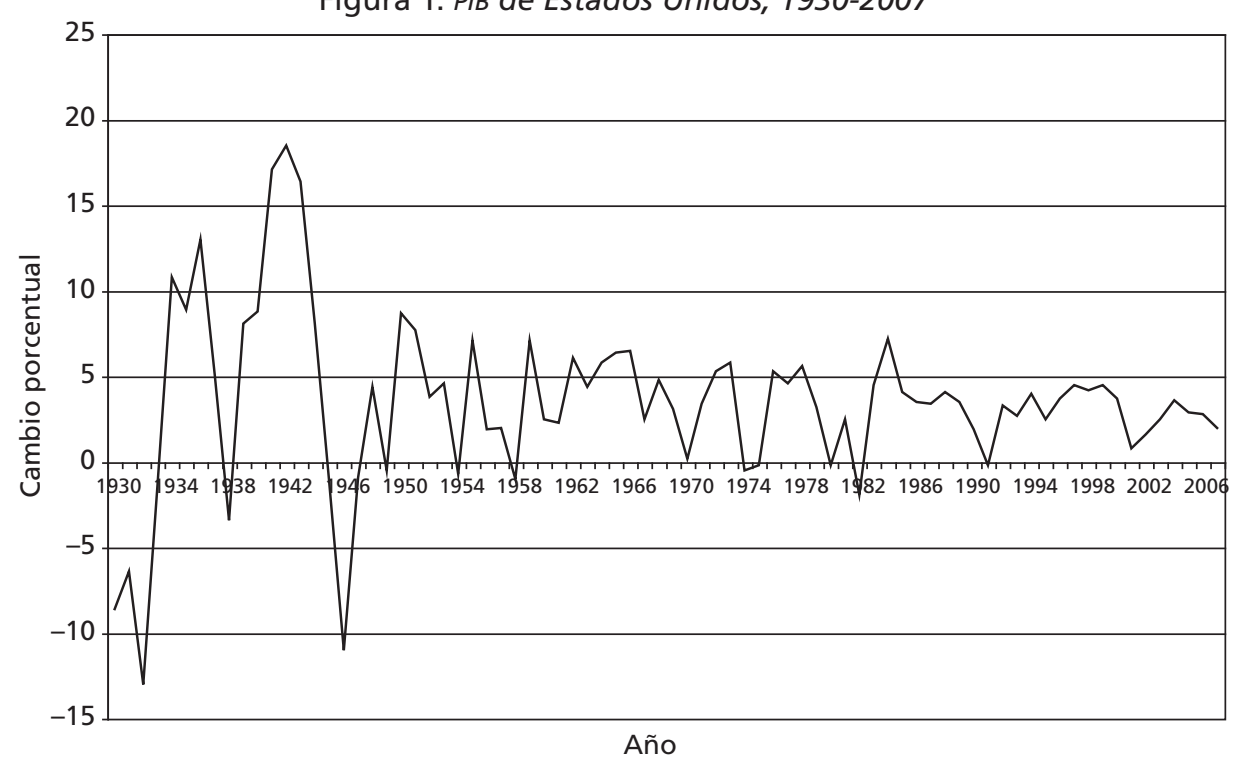


también se identifican en la figura 1: 1990-1991, 2000-2001 y 2007 en adelante. En cuanto a estabilidad económica, el último periodo tiene en promedio una tasa de inflación de $3.1 \%$ anual contra $4.1 \%$ del periodo anterior.

¿Cuáles son las razones precisas que permiten afirmar que la actual crisis financiera da pie para que se abandone la radical idea de que el gobierno no debe interferir con los mercados?

La primera es que en el desarrollo de la crisis financiera fue necesaria la intervención del gobierno de Estados Unidos para evitar el colapso del sistema financiero. Permitir al propio mercado seguir su propia dinámica de ajustes durante las fases críticas a lo largo de 2008 dejó de ser considerado como razonable aun por los economistas y políticos que, por razones de principio, se oponen a la intervención del gobierno en los asuntos de negocios. En realidad, los acontecimientos de quiebra de empresas que se vinieron sucediendo a lo largo de 2008 desbordaron la capacidad de la Reserva Federal y del Tesoro de Estados Unidos para enfrentarlos. A la incertidumbre en la valuación de los activos por parte del mercado, en la que se cayó una vez que se detectó el problema con los valores relacionados con los títulos con respaldo hipotecario (mortgage-backed securities), se agregó la incertidumbre en las reglas de proceder de estos dos organismos. De manera muy crítica se enfrentaron a una disyuntiva: ¿se dejaba caer a una empresa grande - una regla básica del juego de los mercados — y se arriesgaba la salud del sistema, o se le rescataba bajo la otra regla — "demasiado grande para caer"- en cuyo caso se comprometía el futuro de los incentivos y se llegaba a una situación de daño moral? Sólo así se puede entender que durante los primeros meses de 2008 la autoridad se inclinara hacia la primera opción y dejara quebrar a algunas compañías financieras, como ocurrió en el espectacular caso de Lehman Brothers, que salió del mercado en septiembre de 2008, generando de inmediato una espiral muy negativa en los mercados. Tomando en cuenta este precedente, y a partir de entonces, el gobierno se decidió por la segunda opción. En rigor, el gobierno ha intervenido en varios frentes: $i$ ) mediante el programa TARP, aprobado por el Congreso, para buscar sanear y reordenar los circuitos financieros; $\mathrm{ii}$ ) con las masivas inyecciones de liquidez por parte de la Reserva Federal, y iii) con intervenciones directas en los mercados de vivienda para reestructurar las hipotecas y facilitar su pago.

Como ya se ha difundido mucho la secuencia de la crisis, bastará una presentación sintética en la que resaltan las serias fallas que ocurrieron en varios ámbitos de la cadena financiera, en torno del mercado de las hipotecas "subpri$m e$ ". Éste es un mercado de vivienda y edificaciones, importante para un amplio 
sector de familias de bajos recursos y de pequeñas empresas. A partir del desenlace de la crisis previa, que se dio en torno de las empresas tecnológicas, la política de la FED fue mantener tasas de interés en niveles históricamente bajos por un tiempo considerable; este ambiente crediticio impulsó la actividad financiera en relación con este mercado en expansión. Inclusive, algunos economistas llegaron a anticipar que, una vez que se desinflara la burbuja tecnológica en 2001, un campo atractivo para la actividad financiera sería el hipotecario. Una de las principales innovaciones fueron los títulos con respaldo hipotecario, mediante los cuales se "empaquetaron" hipotecas de diversa calidad para mercadearlas, bajo diferentes presentaciones, en Estados Unidos y otras partes del mundo, notoriamente en Europa. El soporte de este mercadeo fue el auge en el sector de la construcción que se daba en el país, pero, a su vez, los altos rendimientos que generaban tales instrumentos provocó un crecimiento de su demanda por parte de bancos, fondos de pensiones, hedge funds, etcétera, que llevó a realimentar este auge de las viviendas. Dentro de esta dinámica de euforia llegó a instaurarse, a decir de Greenspan (2008), un ambiente de relajamiento de las normas y procedimientos, entre ellas, la evaluación del riesgo por parte de las agencias calificadoras, lo que presionó al mismo mercado de vivienda para que perdiera también las reglas establecidas para este tipo de actividad crediticia.

La segunda razón que sustenta la idea del fin de una era se refiere al sesgo tan marcado que se dio en la distribución de los beneficios económicos obtenidos durante esta fase, en favor de un grupo muy reducido de familias. El estudio de Piketty y Saez (2006) muestra que las personas que se llevaron la mayor parte de los beneficios fueron las de los estratos superiores. Por ejemplo, el decil superior aumentó considerablemente su participación en el ingreso, de aproximadamente $32 \%$ en 1982 al inicio de la era Reagan hasta casi $45 \%$ en 2005; de esta manera, se retornó a la situación que imperaba a principios del siglo XX, en la cual la participación era un poco inferior a $45 \%$. Cabe notar que a partir de la Gran Depresión y, sobre todo, con las medidas tomadas por la administración de F. Delano Roosevelt, se dio una primera gran reversión durante la cual los ingresos de la gran mayoría de la población aumentaron.

Este estudio detalla la participación de diferentes percentiles de ingreso, lo cual ayuda a ver que en realidad fueron los estratos de ingresos más altos los que se beneficiaron durante la última época. Por ejemplo, el percentil de ingreso más alto (P99-100) aumentó su participación de 8 a 17\%, mientras que el 0.01\% de unidades con ingresos lo hizo de aproximadamente de $0.65 \%$ en 1980 , a $3 \%$ en 2005. Esta distinción es importante porque, mientras que en los subestratos 
inferiores del decil superior la participación de los ingresos provenientes del salario son los más importantes, en los subestratos superiores la mayor parte de sus ingresos provienen de los ingresos de capital e ingresos empresariales (alrededor de $60 \%$ para el $0.01 \%$ de las unidades con mayores ingresos y $40 \%$ en ingreso salarial). Finalmente, el ingreso promedio de las unidades de la gran mayoría de la población, 99\% de ingresos más bajos, muestra un aumento moderado entre 1982 y 2005; sin lugar a dudas, el aumento más considerable es el del estrato superior, ya que el ingreso promedio de $0.1 \%$ aumenta de cerca de $\$ 300000$ anuales a casi $\$ 800000$ (Piketty y Saez, 2006). ${ }^{1}$

La tercera razón se refiere a los efectos negativos que ha tenido la expansión financiera y la crisis del mundo globalizado, ya sea que se trate de países en los cuales algunos agentes financieros adquirieron valores "tóxicos" de Estados Unidos y que resintieron directamente el efecto de burbuja — sobre todo en la fase de deflación-, o de otras economías que, sin tener una vinculación directa, han sido afectadas por su alta exposición a los flujos financieros, y en las que, al haber seguido las reglas de apertura de la cuenta financiera, los efectos han sido demasiado severos. Tal vez los países que, como China y la India, se abstuvieron de liberalizar sus cuentas de capital y mantuvieron controles sobre los flujos financieros han sido afectados en menor medida. Se puede pensar que estos resultados minan las bases del actual sistema financiero mundial, como se ha cuestionado en las últimas reuniones del Grupo de los 20 (G20).

Finalmente hay que referirnos al contexto político. Ante la evidencia de los malos resultados económicos del gobierno de Bush y la continuación de la guerra en Irak y Afganistán, así como los dramáticos acontecimientos en Wall Street, Obama y el Partido Demócrata ganaron la presidencia y obtuvieron la mayoría en las dos cámaras del Congreso. Con esto, el Partido Republicano quedó en la oposición y en situación de debilidad. A partir de los planteamientos de campaña tanto de Barack Obama como de Hillary Clinton (quienes en combinación con el ex presidente Bill Clinton lograron llevar a su partido unificado a las elecciones), así como por las iniciativas que ha enviado la presidencia al Congreso se pueden observar los siguientes lineamientos del cambio: 1) Se replantea la función del Estado estadounidense en la orientación de la economía en cuestio-

\footnotetext{
${ }^{1}$ La metodología para estimar la evolución de los ingresos es complicada por la existencia de varias formas no monetarias de remuneración del trabajo y de transferencias de ingreso del sector público a las familias; entre otras, los beneficios de la seguridad social, que siguen siendo altos (seguro de desempleo, asistencia social, etcétera); también los beneficios que otorgan las empresas a sus trabajadores, en especial los de seguros médicos.
} 
nes estratégicas en materia de $i$ ) balance económico entre estratos económicos mediante el uso de las políticas fiscal y monetaria; $i$ ) energía y desarrollo sustentable, y iii) reforma al sistema de salud. 2) Se enfrenta la crisis financiera y la recesión mediante programas de estímulos e intervenciones directas para conocer la situación de las entidades bancarias y, de proceder, sanear sus finanzas. 3) Aunque en materia comercial se reivindicaron cambios sustanciales durante las campañas (incluido revisar el TLCAN), la expectativa es que el gobierno no los lleve a cabo.

Por otra parte, es muy interesante notar la concordancia entre el argumento que se ha presentado y el de Pérez (2002), con la gran diferencia de que esta autora lo generaliza para todos los ciclos de largo plazo del sistema capitalista. Según este estudio, se pueden identificar fases en las que la relación entre tecnología, finanzas, crisis y políticas económicas están bien definidas. Por ejemplo, mientras que en la fase de frenesí el capital financiero impone su libertad de acción casi ilimitada, después de la crisis y para entrar en la tercera fase, la situación cambia. En esta fase, el gobierno suele establecer una política de mayores regulaciones a la acción de los financieros, así como limitar los excesos en el acaparamiento de la riqueza generada por parte de los líderes tecnológicos y financieros. En la actualidad, después de la crisis financiera en Wall Street se puede decir que la economía entró en una fase en la cual se viene dando una revisión sustancial de la política de libre mercado de las pasadas dos décadas. Por lo que, de acuerdo con este enfoque, se abre un periodo en el que también economías como la mexicana tienen oportunidad de replantear, dentro de ciertos márgenes, las estrategias comerciales vigentes.

Una vez que se han expuesto las razones para sustentar el cambio, conviene evaluar algunos de los cambios más importantes en la coyuntura de la economía de Estados Unidos que están afectando a la economía mexicana. En el cuadro 1 se presenta información sobre la evolución del PIB de Estados Unidos y algunos componentes principales con el propósito de comparar los indicadores de la crisis actual con los de la anterior de 2001-2002. El hecho más destacado es que mientras que en la anterior recesión el principal factor de la caída económica fue la drástica reducción en la inversión privada $(-7.9 \%)$, de manera notoria la no residencial, en la actual tanto la inversión como el consumo privado se reducen. En el cuadro 2 la información trimestral permite apreciar mejor la dinámica de la recesión. La caída más fuerte se experimenta en el último trimestre de 2008 (a una tasa anualizada de $-6.2 \%$ ), a la cual la contracción de la demanda de consumo privado contribuye con casi la mitad (-3.01) y la inversión privada con 
otro tanto $(-3.11 \%)$. Dada la altísima acumulación de deuda por parte de los agentes privados (familias y empresas), combinado con la drástica caída que se viene experimentando en sus activos (reales y financieros), la necesidad de cubrir sus obligaciones y el grave desarreglo bancario y financiero, se entiende la seria preocupación de que las cifras indiquen apenas el inicio de un ciclo recesivo de larga duración y mayor profundidad. A lo anterior hay que agregar que se espera que la mecánica propia del mercado de bienes raíces sobrepase a la baja los niveles de equilibrio de largo plazo de estos bienes. Sin embargo, hay que notar el altísimo endeudamiento en que está incurriendo el gobierno para contener la dinámica recesiva y estabilizar los mercados financieros. De particular importancia para México es la caída drástica en la demanda de vehículos de transporte y equipo de telecomunicaciones, sectores en los que México aumentó su especialización con el TLCAN.

Cuadro 1. Agregados macroeconómicos de los Estados Unidos Tasas de variación anual, 2001-2008

\begin{tabular}{|c|c|c|c|c|c|c|c|c|}
\hline & 2001 & 2002 & 2003 & 2004 & 2005 & 2006 & 2007 & $2008 \backslash r \backslash$ \\
\hline PIB & 0.8 & 1.6 & 2.5 & 3.6 & 2.9 & 2.8 & 2.0 & 1.1 \\
\hline Gasto de consumo personal & 2.5 & 2.7 & 2.8 & 3.6 & 3.0 & 3.0 & 2.8 & 0.2 \\
\hline $\begin{array}{l}\text { Inversión bruta privada en } \\
\text { el país }\end{array}$ & -7.9 & -2.6 & 3.6 & 9.7 & 5.8 & 2.1 & -5.4 & -6.5 \\
\hline $\begin{array}{l}\text { Inversión bruta fija privada } \\
\text { en el país }\end{array}$ & -3.0 & -5.2 & 3.4 & 7.3 & 6.8 & 1.9 & -3.1 & -4.9 \\
\hline No residencial & -4.2 & -9.2 & 1.0 & 5.8 & 7.2 & 7.5 & 4.9 & 1.7 \\
\hline Estructuras & -2.3 & -17.1 & -4.1 & 1.3 & 1.3 & 8.2 & 12.7 & 11.5 \\
\hline $\begin{array}{l}\text { Equipo para procesamiento } \\
\text { de información y software }\end{array}$ & -4.9 & -6.2 & 2.8 & 7.4 & 9.3 & 7.2 & 1.7 & -3.0 \\
\hline \multicolumn{9}{|l|}{ Otra } \\
\hline Residencial & 0.4 & 4.8 & 8.4 & 10.0 & 6.3 & -7.1 & -17.9 & -20.7 \\
\hline $\begin{array}{l}\text { Gasto público e inversión } \\
\text { bruta pública }\end{array}$ & 3.4 & 4.4 & 2.5 & 1.4 & 0.4 & 1.7 & 2.1 & 2.9 \\
\hline Gobierno general & 3.9 & 7.0 & 6.8 & 4.2 & 1.2 & 2.3 & 1.6 & 6.0 \\
\hline Defensa & 3.9 & 7.4 & 8.7 & 5.8 & 1.5 & 1.6 & 2.5 & 7.2 \\
\hline
\end{tabular}

Fuente: US Department of Commerce. Bureau of Labor Statistics. 


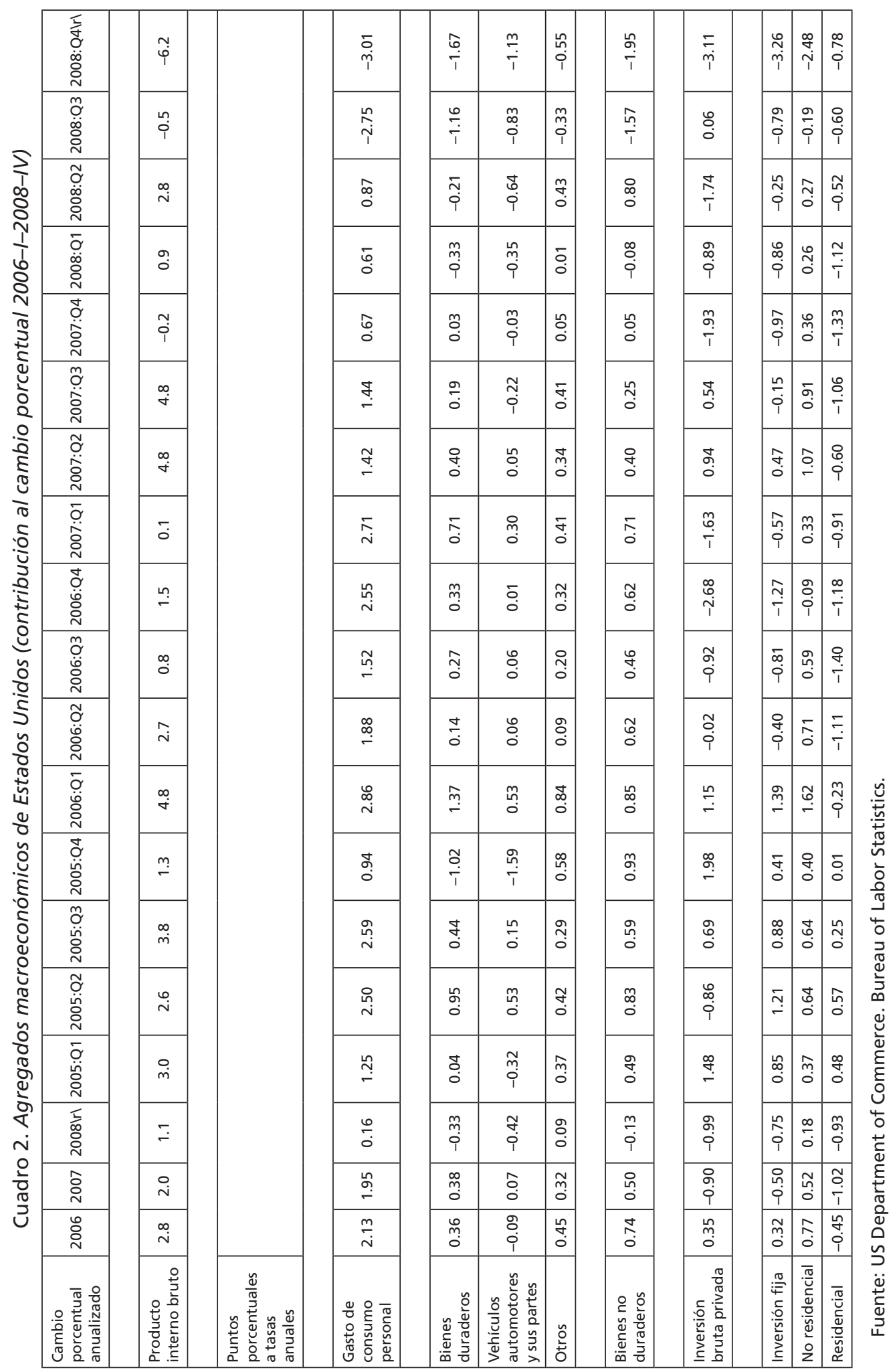




\section{LA FUNCIÓN DE LAS TECNOLOGÍAS DE LA COMUNICACIÓN Y LA INFORMACIÓN}

Como en otros periodos, el sistema capitalista ha mostrado su lado más revolucionario en los recurrentes avances tecnológicos. En el actual, el avance tecnológico en materia de computación, informática y telecomunicaciones no sólo ha permitido revertir el retraso en el crecimiento de la productividad, sino que ofrece palancas muy importantes para pensar en posibles soluciones a las inequidades que también se generan dentro del sistema. Hasta ahora, sin embargo, estos procesos han contribuido a configurar una nueva división internacional del trabajo, de acuerdo con los grados de calificación del personal, en la cual la mejor parte corresponde a aquellos grupos que dominan los mecanismos de generación del conocimiento tecnológico y financiero. Son los avances en estos campos lo que ha llevado a hablar con sustento de una nueva perspectiva: "la economía del conocimiento".

En principio se puede argüir que las TIC seguramente contribuyen a acentuar o agravar disparidades existentes, ya sea entre países, regiones o grupos de personas al interior de los países. Tomando en cuenta que el acceso a estas tecnologías está condicionado por una serie de factores que incluyen la educación, los ingresos familiares y la capacidad de adquisición de equipos para poder hacer uso de estas tecnologías, así como la ubicación geográfica, se entenderá que los grupos mejor posicionados en la sociedad serán quienes se beneficien en mayor medida con estas tecnologías. Dicho de otra manera, los prerrequisitos de educación, habilidades de lenguaje y culturales que permiten aprovechar las ventajas que ofrece la actual sociedad del conocimiento han aumentado considerablemente respecto del pasado reciente. En el caso de países como México, con fuertes y persistentes rezagos en la cobertura de la educación básica que además enfrentan serios obstáculos para reformar su sistema educativo, será más probable que se mantenga o profundice la división basada en la escolaridad. De hecho, en los mismos países ricos, como Estados Unidos, se ha investigado hasta qué punto estas tecnologías son las responsables de la ampliación de la brecha en los ingresos de los trabajadores calificados y no calificados (Rodrik, 1997).

Por otra parte, varios estudios han identificado la potencialidad que ofrecen estas tecnologías para promover el desarrollo económico en países y regiones marginados. Desde una perspectiva económica, estas tecnologías ofrecen oportunidades especiales por varias razones: 
i) Muchas de las tecnologías tienen el carácter de bienes públicos porque la información es un bien no rival y con un bajo grado de exclusión; por ejemplo, el hecho de que los estudiantes de una escuela en alguna comunidad tengan acceso a una enciclopedia electrónica no impide que los estudiantes de las restantes escuelas también se beneficien de dicho conocimiento en forma simultánea; de manera similar, el que una empresa tenga acceso a información sobre un mercado para su producto en la ciudad de México no excluye a otros de tal conocimiento. La existencia de fuertes externalidades asociadas con las tecnologías del conocimiento ha llevado a elaborar nuevos modelos en los cuales se logra superar la restricción impuesta al crecimiento por los rendimientos marginales decrecientes, como en los modelos tradicionales. Pero el equipo de cómputo que permite tener acceso a la enciclopedia es un bien rival porque su uso excluye el uso por otros. Se requiere entonces de casi tantos equipos como usuarios existan. De igual manera, las habilidades y calificaciones de los técnicos e ingenieros en informática son rivales, aunque el conocimiento sobre la operación del sistema no lo es. Por otra parte, los servicios de acceso a internet no son rivales pero son altamente excluyentes porque las compañías proveedoras de los mismos adquieren el derecho de imponer una tarifa por el mismo (Romer, 1990; Jones, 2000/1998 a).

ii) Estas tecnologías se caracterizan también por tener economías de escala que promueven la formación de redes y externalidades asociadas (Torero y Von Braun, 2006).

iii) Las TIC permiten la captura electrónica (o digital), el procesamiento, almacenaje y transmisión de información de manera masiva, flexible y rápida entre casi cualesquiera puntos del planeta; para lograrlo se requiere de equipo de cómputo (hardware y periféricos), software o paquetería de programación, servicio de internet, equipo audiovisual (televisión, videocámaras, entre otros), equipo asociado (fotocopiadoras, máquinas registradoras apropiadas), servicios de telefonía. La configuración de equipo y servicios variará según se trate de usuarios personales o de negocios (pequeños o grandes), pero en cualquier caso se percibe que el desembolso inicial en forma de inversión, así como el gasto corriente, son demasiado altos como para que puedan ser cubiertos por la gran mayoría de las personas y negocios en los países pobres. Esta dificultad se hace mayor cuando, ante carencias básicas, no sería siquiera recomendable el incurrir en este tipo de gastos "superfluos". Dentro de un país es también 
de esperar que estos montos de inversión y costos sean más altos en regiones rurales que en los centros urbanos, por las economías de aglomeración que se disfrutan en éstos.

De aquí se desprende la conveniencia de diseñar e implantar políticas públicas que se orienten a apoyar la adquisición de una infraestructura básica y reducir los costos de los servicios, aunque en algunos estudios se pone en duda la racionalidad de los gobiernos al asignar sus escasos recursos a este tipo de gastos en lugar de canalizarlos hacia los más básicos de salud, alimentación y educación (Torero y Von Braun, 2006). Además, para muchos países resultará imposible abordar dichas políticas sin el apoyo de organismos internacionales como el Banco Mundial y el BID, entre otros. ${ }^{2}$

En vista de los altos costos de acceso a estas tecnologías, ¿cuáles son las ventajas que ofrecen para superar la diversidad de problemas inherentes al subdesarrollo? Aquí me refiero tan sólo a dos problemas clave: la productividad y la educación apropiada al periodo actual. En el mundo de las pequeñas y medianas empresas, estas tecnologías pueden aumentar la productividad a partir de los siguientes mecanismos: $i$ ) de manera directa, mediante el uso de los recursos de computación e internet; $i$ ) de manera indirecta, mediante la formación de redes para aprovechar la información y las externalidades que se generan por este proceso. En el mundo de las Pymes, sin embargo, se pueden encontrar muchas y fuertes resistencias para cambiar sus modelos de negocios y formas de operación; no sólo por los altos costos y los resultados inciertos sino también por el ambiente de desconfianza que pueda existir en varios sectores respecto a los programas de gobierno. En el caso mexicano, una fuente de resistencia radica en la oposición de muchos negocios que operan en actividades informales a ser captados por organismos de gobierno, como la Secretaría de Hacienda y el IMSS, entre otros. El ambiente de la competencia puede también desfavorecer a industrias importantes en un país frente a los líderes en el manejo de las TIC; tal es el caso del sector turismo en México, donde persiste el dominio de agencias extranjeras en el comercio electrónico de los lucrativos servicios turísticos.

Finalmente, uno de los obstáculos más serios en el medio de las telecomunicaciones siguen siendo las limitaciones y las altas tarifas de los servicios de

\footnotetext{
${ }^{2}$ El Banco Mundial y la Corporación Financiera Internacional han establecido el Departamento de Información Global y Tecnologías de la Comunicación con el objetivo de promover el acceso a las TIC y de utilizar recursos a disposición de estas organizaciones para promover la reducción de la pobreza y el desarrollo económico.
} 
acceso a internet. Para efectos de comparación se puede hacer referencia al costo de una canasta de servicios de internet en Corea, un país que a principios de esta década estableció una estrategia para masificar el acceso a la red de banda ancha, y en México. En Corea el costo es de 9.7 dólares mientras que en México se estima en 22.6 dólares; el porcentaje de escuelas con conexiones a internet en México es de 60\%; en Corea, de 99\% (ver cuadros de países en Banco Mundial, 2006).

\section{CRISIS DE LARGA DURACIÓN Y CRECIMIENTO EXCLUYENTE}

En este trabajo se utiliza un esquema de interpretación que caracteriza la situación de la economía como una crisis de larga duración a la cual se ha sobrepuesto la actual grave crisis coyuntural. La primera se manifiesta en marcadas insuficiencias en el crecimiento del ingreso, la productividad y el empleo formal, así como en la persistente migración de mexicanos a Estados Unidos y a las actividades informales. Esto se puede interpretar como que, de la población expulsada del sector agropecuario, sólo una pequeña parte de la que ha migrado al medio urbano en el país ha sido absorbida en la industria; gran parte ha buscado ocupación en actividades informales o ha migrado al exterior del país, principalmente a Estados Unidos. Según estimaciones de Homeland Security (2006), en 2005 había 10.5 millones de personas no autorizadas para estar en el país, de las cuales casi 6 millones habían nacido en México; en 2000, las cifras respectivas eran de 8.5 millones y 4.7 millones. Es decir, en el primer quinquenio del milenio se estimaba un flujo anual promedio de 260 mil mexicanos migrantes ilegales. De acuerdo con la oficina del censo se estima que otros 150 mil mexicanos migran legalmente al año a Estados Unidos (U. S. Census, 2000, véase Homeland Security, 2006). Ahora bien, dentro de la población que permanece en el medio rural, una alta proporción se encuentra en condiciones de pobreza e indigencia. De acuerdo con las estimaciones del Comité Técnico para la Medición de la Pobreza de Sedesol, poco más de $20 \%$ de los individuos caían en una situación de pobreza en las zonas urbanas y $50 \%$ en las zonas rurales de México. ${ }^{3}$

Esta situación se da dentro de un marco de estabilidad macroeconómica que se ha alcanzado a partir de unos años después de la grave crisis cambiaria y bancaria acontecida hace poco más de un decenio. En realidad, México, al igual

\footnotetext{
${ }^{3}$ En esta categoría de pobreza se incluye a todas aquellas personas cuyo consumo no alcanza el segundo umbral que se define y que corresponde al valor de la canasta alimentaria, más una estimación de los gastos que se consideran necesarios en salud, vestido, calzado, vivienda, transporte y educación (Sedesol, 2002).
} 
que otros países, recibe el fuerte impacto de la crisis estadounidense de 2007 en forma rezagada. Como el país no estaba directamente vinculado con los activos "tóxicos", como sí era el caso de los europeos durante los primeros meses de 2008 , los efectos económicos fueron menores. Fue a partir del verano del año pasado cuando el país, al igual que otras economías emergentes (Brasil, Argentina, Corea del Sur) con libre movilidad de capitales, empezó a experimentar fuertes salidas de capital, lo que provocó grandes devaluaciones e inestabilidad cambiaria. Unos meses después vendría el impacto a partir de los canales comerciales, como se verá al final de esta sección.

Al retomar el estudio de la crisis de largo plazo, vemos que México no ha tenido un buen desempeño económico ni en términos absolutos ni cuando se le compara con otras economías. Para tener una mejor perspectiva de su desempeño, el cuadro 3 presenta una síntesis de la evolución del PIB por persona ocupada, a partir de 1950. Con base en las cifras de PWT6.2, se observa un pobre desempeño de la productividad laboral (PIB por trabajador de la PEA) para los últimos 50 años, de apenas un crecimiento promedio anual de $1.52 \%$. Éste es el resultado de un contraste de tres periodos: entre 1950 y 1980 el crecimiento alcanzó 3.32\% anual, el cual sin ser sobresaliente es considerablemente superior a $1.24 \%$ correspondiente al periodo posterior a 1990 . Se separa el periodo correspondiente a la década de los ochenta, con un desempeño negativo, por considerar que en gran medida es el resultado de la crisis financiera que estalla en 1981 y gene-

Cuadro 3. Desempeño de la economía mexicana por periodos. 1950-2007 (PIB por persona. Tasa de crecimiento promedio anual). Porcentaje

\begin{tabular}{|l|c|c|c|c|c|}
\hline & Población & PIB & PIB per cápita* & $\begin{array}{c}\text { PIB per } \\
\text { cápita** }\end{array}$ & $\begin{array}{c}\text { PIB por } \\
\text { trabajador*** }\end{array}$ \\
\hline & PWT6.2 & & PWT6.2 & INEGI & PWT6.2 \\
\hline $\mathbf{1 9 5 0 - 2 0 0 7}$ & 2.38 & 4.58 & 2.20 & & 2.20 \\
\hline $\mathbf{1 9 5 0 - 1 9 8 0}$ & 2.96 & 6.53 & 3.57 & 3.38 & 3.59 \\
\hline $\mathbf{1 9 8 0 - 1 9 9 0}$ & 2.19 & 1.40 & -0.80 & -0.50 & -1.06 \\
\hline $\mathbf{1 9 9 0 - 2 0 0 0}$ & 1.64 & 3.58 & 1.94 & & 1.91 \\
\hline $\mathbf{1 9 9 0 - 2 0 0 7}$ & 1.46 & 3.07 & 1.60 & & 1.70 \\
\hline
\end{tabular}

Fuente: procesado a partir de la información PWT6.2. Center for International Comparisons of Production. Income and Prices (CIC). University of Pennsylvania e INEGI.

* Índice Laspeyres.

** Con base en la serie histórica del PIB, 1950-1995 y población PWT6.2.

*** El número de trabajadores se refiere a la PEA. 
ra la fuerte inestabilidad económica, y también porque no es sino hasta 19851987 que se inicia claramente el modelo de orientación hacia el exterior.

Se pueden identificar tres tipos de causas del desempeño económico del país: la recurrencia de las crisis económicas, en especial en su dimensión cambiaria y financiera, la insuficiencia de la acumulación de capital y el problema de la productividad. En torno de las crisis recordemos las últimas, acontecidas en 1987, 1994-1995, 2001-2002, y la actual, 2008-2009. Aquí sólo procede dejar sentado el efecto negativo de estos episodios, independientemente de los orígenes de los mismos.

De naturaleza distinta es el deficiente comportamiento de la acumulación de capital. En el cuadro 4 se describe el comportamiento de la inversión fija. Las tasas de participación de la FBKF en el PIB oscilan alrededor de $20 \%$, con algunos años ligeramente por arriba de esta cifra, pero en su mayoría por debajo. Estos coeficientes son relativamente bajos cuando se comparan con los correspondientes a economías asiáticas, como China y Corea del Sur, que superan $30 \%$. En cuanto a su composición se observa una tendencia al alza de la inversión privada hasta 2001, lo cual es congruente con la política de reducción en la participación del Estado en la economía. Entre 2002 y 2004, durante la administración de Fox, hubo un ligero repunte de la inversión pública.

El problema de la productividad es de más largo plazo. Efectivamente, desde la época de la estrategia sustitutiva de importaciones se detectó que el rápido crecimiento era de tipo extensivo, es decir, con considerable expansión de los factores de la producción, pero con lento crecimiento de la productividad de los factores. Este fenómeno fue interpretado como resultado de las limitaciones del crecimiento orientado hacia el mercado interno. Así, como consecuencia de la sobrevaluación de la moneda, se identificaron deficiencias en materia del aprovechamiento de las economías de escala, ineficiencias técnicas debido a la falta de competencia y selección inadecuada de técnicas (Hernández Laos, 1985).

En el cuadro 5 se presentan indicadores sobre valor agregado, población ocupada y productividad laboral para el periodo 1988-2004, con información del Sistema de Cuentas Nacionales. Para este periodo, de acuerdo con las estimaciones que realiza el INEGI, el crecimiento promedio de la productividad laboral es de $1.27 \%$. Este lento crecimiento de la productividad, empero, es el resultado de fuertes disparidades sectoriales. Dejando de lado el sector de la minería, por su baja participación en la actividad económica, sobresale el conjunto de actividades manufactureras con un crecimiento promedio anual de la productividad de $2.6 \%$. Este sector muestra un crecimiento del valor agregado (VA) por arriba del 
Cuadro 4. Formación bruta de capital fijo como proporción del PIB y composición en privada y pública

\begin{tabular}{|c|c|c|c|c|}
\hline Año & FBKF/PIB (\%) * & FBKF/PIB (\%) ** & $\begin{array}{c}\text { FBKF-privada } \\
\text { (porcentaje del total) }\end{array}$ & $\begin{array}{l}\text { FBKF-pública } \\
\text { (porcentaje del } \\
\text { total) }\end{array}$ \\
\hline 1988 & 18.52 & & 76.24 & 23.76 \\
\hline 1989 & 17.25 & & 75.63 & 24.37 \\
\hline 1990 & 17.88 & & 76.09 & 23.91 \\
\hline 1991 & 18.65 & & 78.23 & 21.77 \\
\hline 1992 & 19.60 & & 80.69 & 19.31 \\
\hline 1993 & 18.56 & & 79.73 & 20.27 \\
\hline 1994 & 19.35 & & 74.11 & 25.89 \\
\hline 1995 & 16.15 & & 76.78 & 23.22 \\
\hline 1996 & 17.86 & & 83.21 & 16.79 \\
\hline 1997 & 19.52 & & 84.14 & 15.86 \\
\hline 1998 & 20.90 & & 86.62 & 13.38 \\
\hline 1999 & 21.19 & & 85.83 & 14.17 \\
\hline 2000 & 21.38 & & 83.21 & 16.79 \\
\hline 2001 & 20.00 & & 81.96 & 18.04 \\
\hline 2002 & 19.25 & & 77.96 & 22.04 \\
\hline 2003 & 18.93 & 18.94 & 76.02 & 23.98 \\
\hline 2004 & 19.65 & 19.74 & 76.36 & 23.64 \\
\hline 2005 & & 20.11 & & \\
\hline 2006 & & 20.79 & & \\
\hline
\end{tabular}

Fuente: INEGI. Sistema de Cuentas Nacionales.

* SCN. Base 1993.

** SCN. Base 2003.

promedio, mientras que su población ocupada remunerada (POR) crece ligeramente por debajo del promedio correspondiente. Esta división contribuye con alrededor de una quinta parte al valor agregado total y con $12.8 \%$ de la POR en 2001. Se confirma que su actividad no ha sido tan dinámica como para haberse constituido en un polo de fuerte generación de empleo.

Dado que este periodo está caracterizado por un crecimiento insuficiente de la producción y del empleo, la expansión de la ocupación en actividades informales de baja productividad se va a manifestar en el comportamiento débil de la productividad en sectores que se localizan en las actividades de comercio y 
de servicios (comercio ambulante, comercio al por menor, servicio doméstico, entre otros). Poco más de una cuarta parte de la PO se localiza en actividades económicas que se agrupan en los servicios comunales sociales y personales (servicios profesionales, de educación, médicos, de esparcimiento, de administración pública y de defensa).

Cuadro 5. Indicadores del crecimiento de la productividad laboral por gran división. 1988-2004

\begin{tabular}{|c|c|c|c|c|c|c|c|c|}
\hline & \multicolumn{2}{|c|}{$\begin{array}{c}\text { Participación } \\
\text { en el valor } \\
\text { agregado }\end{array}$} & \multicolumn{2}{|c|}{$\begin{array}{c}\text { Participación en la } \\
\text { población ocupada } \\
\text { remunerada }\end{array}$} & \multirow{2}{*}{$\begin{array}{c}\text { Tasa de } \\
\text { crecimiento } \\
\text { del valor } \\
\text { agregado } \\
\text { (1988- } \\
2001)\end{array}$} & \multirow{2}{*}{$\begin{array}{c}\text { Tasa de } \\
\text { crecimiento } \\
\text { de la } \\
\text { población } \\
\text { ocupada } \\
\text { remunerada } \\
(1988-2001)\end{array}$} & \multicolumn{2}{|c|}{$\begin{array}{c}\text { Tasa de crecimiento } \\
\text { de la productividad } \\
\text { laboral }\end{array}$} \\
\hline & 1988 & 2000 & 1988 & 2000 & & & 1988-2001 & $1988-2004$ \\
\hline Total & & & 24069999 & 31993581 & 3.35 & 2.19 & 1.14 & 1.27 \\
\hline $\begin{array}{l}\text { Agropecuario. } \\
\text { silvicultura } \\
\text { y pesca }\end{array}$ & 7.78 & 4.01 & 26.01 & 19.65 & 2.05 & 0.12 & 1.93 & 1.75 \\
\hline Minería & 2.91 & 1.39 & 0.76 & 0.41 & 1.88 & -2.68 & 4.68 & 4.27 \\
\hline Manufacturas & 23.50 & 20.10 & 12.61 & 12.82 & 4.22 & 1.95 & 2.23 & 2.60 \\
\hline Construcción & 3.93 & 5.12 & 8.06 & 12.33 & 2.48 & 5.33 & -2.70 & -1.91 \\
\hline $\begin{array}{l}\text { Electricidad, } \\
\text { gas y agua }\end{array}$ & 1.29 & 1.09 & 0.55 & 0.55 & 3.20 & 2.39 & 0.79 & 1.24 \\
\hline $\begin{array}{l}\text { Comercio, } \\
\text { restaurantes } \\
\text { y hoteles }\end{array}$ & 24.97 & 21.14 & 16.29 & 18.53 & 3.47 & 3.43 & 0.04 & 0.34 \\
\hline $\begin{array}{l}\text { Transporte, } \\
\text { almacenaje y } \\
\text { comunicaciones }\end{array}$ & 9.32 & 11.04 & 5.27 & 6.05 & 5.33 & 3.42 & 1.84 & 2.51 \\
\hline $\begin{array}{l}\text { Servicios } \\
\text { financieros, } \\
\text { seguros, } \\
\text { actividades } \\
\text { inmobiliarias } \\
\text { y de alquiler }\end{array}$ & 9.55 & 12.01 & 2.06 & 1.89 & 3.87 & 1.66 & 2.18 & 2.37 \\
\hline $\begin{array}{l}\text { Servicios } \\
\text { comunales, } \\
\text { sociales } \\
\text { y personales }\end{array}$ & 16.76 & 24.10 & 28.39 & 27.78 & 2.01 & 2.02 & -0.01 & 0.01 \\
\hline
\end{tabular}

Fuente: procesado a partir del INEGI. Sistema de Cuentas Nacionales. 
Otros estudios corroboran el mal desempeño de la productividad y comparten la sorpresa por el pésimo resultado en un país que ha implantado las reformas de mercado. Bosworth (1998) realiza dos estimaciones de la productividad laboral tomando en cuenta la información directa de la fuerza laboral y con base en la información de puestos de trabajo del SCN para varios subperiodos entre 1960 y 1995, lo que arrojó en ambos casos resultados modestos. Visto desde otro ángulo, Hernández y Guzmán (2005) analizan la evolución de los niveles de productividad industrial en comparación con los correspondientes en Estados Unidos, con el fin de poner a prueba la hipótesis de convergencia. Encuentran que, para el periodo 1975-1995, no se dio prácticamente convergencia, aunque se puede detectar un pequeño grupo de industrias "selectas" que sí han mostrado ganancias de productividad relativas a las industrias correspondientes en Estados Unidos

En Estrada y Arriaga (2005) se analiza una serie de contrastes en la evolución de la productividad. Sobresale la división de las industrias metálicas básicas con un crecimiento excepcional de la productividad cercano a $8.5 \%$, superior en más de cinco puntos porcentuales al crecimiento que registra el resto de las divisiones. También sobresale, en primer lugar, un grupo de industrias dinámicas con fuerte crecimiento de la producción y avance en la productividad que incluye principalmente a las altamente exportadoras, como las de vehículos automotores, equipos y aparatos electrónicos, y las de maquinaria y aparatos eléctricos. En contraste, hay un segundo grupo con pobre desempeño, e incluye ramas intensivas en trabajo de baja calificación, como la textil de prendas de vestir y productos de cuero y calzado, aunque su contribución al empleo fue importante al aumentar entre 1988 y 2001 de 7 a 10\%. Un tercer grupo es relevante y curioso, al registrar crecimientos de la productividad por arriba del promedio manufacturero, pero como resultado de fuertes caídas en la producción y el empleo, dentro de las cuales están la petroquímica básica y los fertilizantes, la caída en la producción interna se cubre con importaciones crecientes. Otro grupo de industrias presenta patrones menos definidos o más irregulares.

En cuanto a las perspectivas de la actual crisis y la afectación a la economía mexicana, se puede decir lo siguiente: a diferencia de la crisis económica acontecida en 2001, de corta duración y seguida por una recuperación relativamente rápida y, sobre todo, que no provocó gran dislocación de los mercados financieros, la severidad de la actual crisis tendrá efectos mayores y más duraderos en la economía mexicana. Ya vimos en la sección anterior la declinación sincronizada de todos los componentes de la demanda agregada de la economía estadounidense en los últimos trimestres de 2008. 
Los efectos negativos se producen tanto a partir de los canales comerciales como de los financieros y cambiarios. La recesión en Estados Unidos y en el mundo en su conjunto ha provocado, inmediata y directamente, la caída de las exportaciones de bienes que se fabrican en México, una drástica baja en el precio de la mezcla mexicana de crudo y una baja sustancial en la actividad industrial, de manera destacada en la IME, pero también en el sector automotriz y el electrónico y de telecomunicaciones. Como se aprecia en el cuadro 6, después de un incremento sólido de las exportaciones entre enero de 2007 y enero de 2008 $(17.02 \%)$, las exportaciones presentaron un desplome que representa más de $30 \%$ entre enero de 2008 y enero de 2009; la caída más pronunciada se produjo en los ingresos por venta de petróleo crudo $(-55.28 \%)$, seguido por el de manufacturas $(-26.81 \%)$; más reveladoras son las cifras de la participación porcentual de cada rubro exportador en el total de la baja de ingresos por exportaciones. El sector manufacturero es responsable de casi dos terceras partes, seguida por las petroleras con casi $30 \%$; por cierto que las exportaciones agropecuarias tienen una contribución muy pequeña, de aproximadamente $-1 \%$. Debido a la fuerte interrelación entre las exportaciones y las importaciones, además del efecto de caída de la producción nacional, las importaciones también cayeron en proporciones semejantes; las totales y las de uso intermedio caen en aproximadamente $-30 \%$, mientras que las de consumo en $-44 \%$ y las de capital en $-10.32 \%$. La mayor contribución a la caída se originó en las importaciones de uso intermedio, con casi $72 \%$ del total.

Para concluir esta sección es necesario referirnos a una característica destacada del actual patrón de crecimiento. Por una parte, esta estrategia ha generado resultados positivos para un sector de la sociedad mexicana. Efectivamente, hay un grupo de empresas que han obtenido altos beneficios durante estos años, la mayor parte de propiedad extranjera pero también algunas de mexicanos. De hecho, algunas corporaciones mexicanas han extendido sus actividades al plano global, con lo que aprovechan el juego de los mercados y compiten exitosamente. Este sector corporativo orienta su actividad a los mercados externos en sectores diversos que incluyen principalmente la IME, la manufactura de productos de mediana tecnología como los automotrices, electrónicos y de telecomunicaciones, así como servicios turísticos. ${ }^{4}$ De gran importancia para estos gru-

\footnotetext{
${ }^{4}$ Algunos ejemplos de estos negocios en la industria son: alimentos: Grupo Alfa, Grupo Bimbo; bebidas: Femsa, fomento económico; minerales no metálicos: Cemex y Vitro, pero en especial en los servicios de telecomunicaciones donde destaca el grupo Carso Global Telecom y América Telecom y, en menor medida, los grupos televisivos.
} 


\begin{tabular}{|c|c|c|c|c|c|c|c|c|c|c|c|c|c|c|c|c|c|c|c|c|c|c|c|c|c|c|}
\hline & 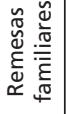 & $\begin{array}{c}\stackrel{\infty}{\infty} \\
\underset{\infty}{\infty} \\
\sim \\
\sim\end{array}$ & $\begin{array}{l}\stackrel{N}{\hat{0}} \\
\dot{\infty} \\
\infty \\
-\end{array}$ & $\begin{array}{l}\bar{m} \\
\dot{\infty} \\
\stackrel{\infty}{\sim} \\
\stackrel{\sim}{*}\end{array}$ & $\begin{array}{l}\frac{N}{\sigma o} \\
\stackrel{\delta}{\sim} \\
\sim\end{array}$ & 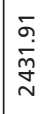 & \begin{tabular}{|l|}
0 \\
$\tilde{n}$ \\
0 \\
0 \\
$\sim$ \\
$n$
\end{tabular} & \begin{tabular}{|l|}
$\stackrel{n}{n}$ \\
$\dot{\delta}$ \\
$\stackrel{0}{\sim}$ \\
$\sim$
\end{tabular} & 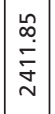 & $\begin{array}{l}\hat{\sigma} \\
\dot{\alpha} \\
\stackrel{\infty}{\sim} \\
\stackrel{\sim}{N}\end{array}$ & $\begin{array}{l}g \\
\stackrel{g}{0} \\
\stackrel{0}{N} \\
\sim\end{array}$ & 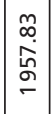 & \begin{tabular}{l}
$\infty$ \\
0 \\
0 \\
$o$ \\
$o$ \\
\hdashline
\end{tabular} & 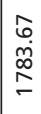 & 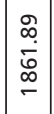 & 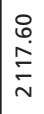 & $\begin{array}{l}g \\
\infty \\
\infty \\
\infty \\
\sim\end{array}$ & 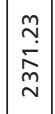 & 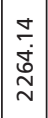 & $\begin{array}{l}\mathscr{Q} \\
\stackrel{0}{0} \\
\infty \\
\sim \\
\sim\end{array}$ & 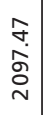 & 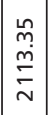 & $\begin{array}{l}\mathbf{b} \\
\dot{0} \\
0 \\
0 \\
\sim\end{array}$ & 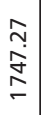 & & 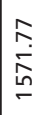 \\
\hline \multirow{4}{*}{ 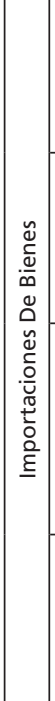 } & 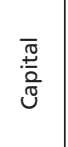 & 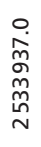 & $\begin{array}{l}\dot{0} \\
\dot{d} \\
\tilde{N} \\
\tilde{N} \\
\sim\end{array}$ & 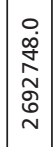 & 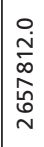 & $\begin{array}{l}0 \\
\tilde{j} \\
\tilde{\infty} \\
\hat{\omega} \\
\infty \\
\sim \\
\sim\end{array}$ & $\mid \begin{array}{l}0 \\
0 \\
0 \\
0 \\
\Phi \\
\Phi \\
\infty \\
\sim\end{array}$ & $\mid \begin{array}{l}0 \\
0 \\
\hat{h} \\
0 \\
0 \\
0 \\
0 \\
0 \\
N\end{array}$ & 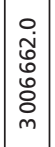 & 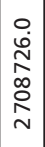 & 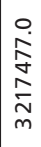 & $\mid \begin{array}{l}0 \\
\dot{0} \\
\dot{m} \\
\dot{s} \\
\dot{m}\end{array}$ & 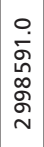 & 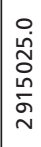 & 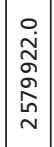 & 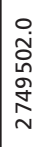 & $\begin{array}{l}\text { O. } \\
\stackrel{0}{0} \\
\stackrel{0}{0} \\
\text { m }\end{array}$ & $\mid \begin{array}{l}0 \\
\dot{0} \\
o \\
o \\
0 \\
\tilde{m} \\
\end{array}$ & $\mid \begin{array}{l}0 \\
o \\
o \\
o \\
o \\
o \\
0 \\
m\end{array}$ & $\mid \begin{array}{l}0 \\
\bar{\vdots} \\
\hat{\alpha} \\
o \\
o \\
m\end{array}$ & 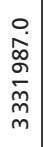 & 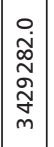 & 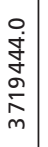 & 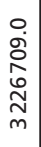 & & 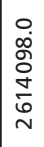 \\
\hline & 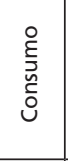 & 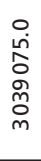 & $\begin{array}{l}0 \\
\dot{d} \\
0 \\
\\
\infty \\
\sim\end{array}$ & 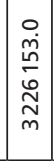 & 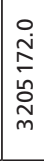 & 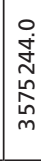 & 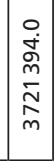 & $\mid \begin{array}{l}0 \\
\stackrel{\sim}{\sim} \\
\tilde{D} \\
\tilde{D} \\
m\end{array}$ & 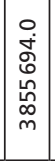 & $\begin{array}{c}0 \\
\dot{1} \\
\vdots \\
\hat{O} \\
m \\
m\end{array}$ & 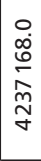 & $\mid \begin{array}{c}0 \\
\dot{d} \\
\stackrel{D}{ } \\
\stackrel{N}{\sigma} \\
\dot{\sigma}\end{array}$ & $\begin{array}{l}0 \\
\infty \\
\infty \\
o \\
0 \\
\tilde{m} \\
\sigma \\
\sigma\end{array}$ & 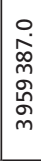 & 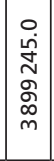 & 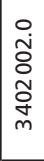 & $\begin{array}{l}\stackrel{O}{\dot{j}} \\
\stackrel{\sigma}{\sim} \\
\underset{\sim}{\sim}\end{array}$ & \begin{tabular}{|c|}
0 \\
$\dot{\bar{m}}$ \\
$\bar{c}$ \\
$\underline{0}$ \\
$\infty$ \\
$m$ \\
\end{tabular} & $\mid \begin{array}{c}0 \\
\stackrel{0}{0} \\
\underline{m} \\
\tilde{n} \\
\tilde{\infty} \\
m\end{array}$ & $\mid \begin{array}{l}0 \\
\stackrel{i}{i} \\
\hat{i} \\
\hat{n} \\
\frac{\sigma}{\sigma}\end{array}$ & $\begin{array}{l}0 \\
\stackrel{0}{0} \\
\grave{N} \\
\sigma \\
\vdots \\
\dot{\sigma}\end{array}$ & $\left|\begin{array}{c}0 \\
\infty \\
\infty \\
\infty \\
o \\
o \\
\sigma \\
\sigma\end{array}\right|$ & $\begin{array}{l}0 \\
\dot{0} \\
0 \\
0 \\
\stackrel{0}{m} \\
\forall\end{array}$ & $\begin{array}{c}0 \\
\dot{\vdots} \\
\vdots \\
\vdots \\
\grave{o} \\
m\end{array}$ & & 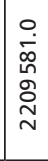 \\
\hline & 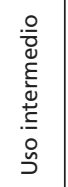 & 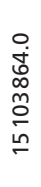 & 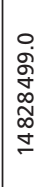 & 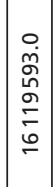 & 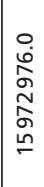 & $\begin{array}{l}\stackrel{0}{0} \\
\hat{\infty} \\
\stackrel{\infty}{0} \\
\frac{0}{\infty} \\
\stackrel{\infty}{0}\end{array}$ & 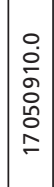 & $\mid \begin{array}{c}0 \\
\infty \\
0 \\
m \\
\tilde{D} \\
\tilde{m} \\
\underline{\Sigma}\end{array}$ & 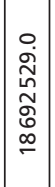 & 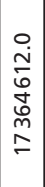 & 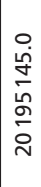 & 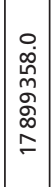 & 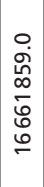 & $\mid \begin{array}{l}\stackrel{0}{0} \\
\stackrel{N}{N} \\
\stackrel{N}{\Sigma} \\
\end{array}$ & 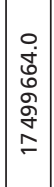 & 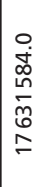 & 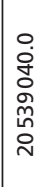 & 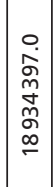 & 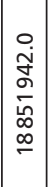 & $\begin{array}{c}0 \\
\stackrel{0}{ } \\
\stackrel{1}{o} \\
\infty \\
\infty \\
o \\
\stackrel{N}{ }\end{array}$ & 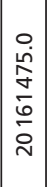 & 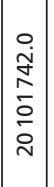 & 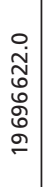 & $\begin{array}{l}\circ \\
\stackrel{\dot{D}}{\tilde{N}} \\
\tilde{U} \\
\dot{\tilde{U}} \\
\stackrel{0}{0}\end{array}$ & & 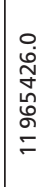 \\
\hline & $\begin{array}{l}\frac{\breve{\omega}}{\pi} \\
\stackrel{0}{\circ}\end{array}$ & $\begin{array}{l}0 \\
0 \\
0 \\
0 \\
0 \\
0 \\
0 \\
\stackrel{0}{N}\end{array}$ & 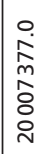 & 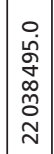 & $\begin{array}{l}0 \\
0 \\
0 \\
o \\
o \\
\sim \\
\infty \\
\infty \\
\sim \\
\sim\end{array}$ & $\begin{array}{l}0 \\
\hat{H} \\
\infty \\
\infty \\
\omega \\
\tilde{N} \\
\stackrel{N}{~}\end{array}$ & 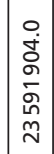 & $\mid \begin{array}{l}0 \\
\dot{\dot{d}} \\
\mathbf{D} \\
\tilde{\tilde{D}} \\
\tilde{N} \\
\tilde{N}\end{array}$ & 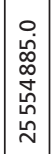 & $\mid \begin{array}{c}0 \\
\infty \\
0 \\
0 \\
o \\
\hat{N} \\
\tilde{N}\end{array}$ & 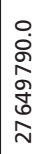 & $\mid \begin{array}{c}0 \\
\dot{\alpha} \\
\infty \\
\tilde{N} \\
\hat{N} \\
\stackrel{\omega}{N}\end{array}$ & 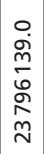 & 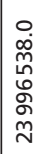 & $\begin{array}{l}0 \\
\dot{\dot{m}} \\
\infty \\
\infty \\
\infty \\
\tilde{N} \\
\tilde{N}\end{array}$ & $\begin{array}{l}0 \\
\infty \\
\infty \\
\infty \\
\infty \\
\infty \\
\infty \\
\sim\end{array}$ & $\begin{array}{l}0 \\
\infty \\
\infty \\
\infty \\
\tilde{N} \\
\stackrel{\infty}{\infty} \\
\stackrel{n}{N}\end{array}$ & 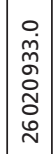 & 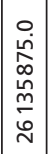 & 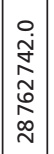 & 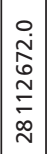 & 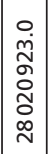 & $\begin{array}{l}0 \\
\dot{j} \\
\stackrel{j}{N} \\
\bar{N} \\
\grave{N}\end{array}$ & 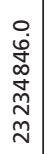 & & 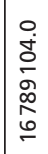 \\
\hline \multirow{4}{*}{ 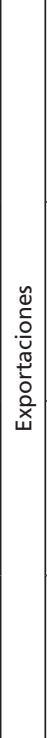 } & 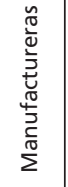 & 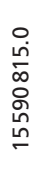 & $\begin{array}{l}\stackrel{0}{\infty} \\
\tilde{N} \\
o \\
o \\
o \\
\stackrel{0}{\sim}\end{array}$ & 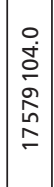 & $\begin{array}{l}0 \\
\dot{m} \\
\tilde{n} \\
\tilde{\sigma} \\
\tilde{\sigma} \\
\underline{\sigma}\end{array}$ & 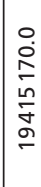 & 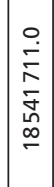 & $\mid \begin{array}{c}0 \\
\dot{\sigma} \\
\bar{m} \\
\stackrel{\infty}{-} \\
\stackrel{\infty}{-}\end{array}$ & 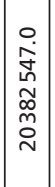 & 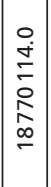 & $\begin{array}{l}0 \\
\dot{m} \\
\frac{j}{d} \\
\stackrel{o}{0} \\
\frac{0}{N}\end{array}$ & 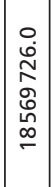 & $\mid \begin{array}{c}0 \\
\dot{N} \\
\hat{\Lambda} \\
\tilde{\alpha} \\
\stackrel{\alpha}{\infty} \\
\sim\end{array}$ & 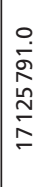 & 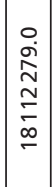 & 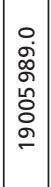 & $\mid \begin{array}{l}0 \\
\stackrel{d}{\infty} \\
\stackrel{m}{m} \\
\stackrel{m}{m} \\
\stackrel{\sim}{N}\end{array}$ & 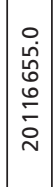 & 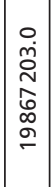 & $\begin{array}{l}0 \\
\stackrel{0}{0} \\
0 \\
\circ \\
\circ \\
\circ \\
\stackrel{N}{ }\end{array}$ & $\begin{array}{l}0 \\
\dot{0} \\
0 \\
0 \\
\infty \\
\grave{0} \\
\sigma \\
\sigma\end{array}$ & $\mid \begin{array}{l}0 \\
\dot{0} \\
0 \\
0 \\
0 \\
\hat{O} \\
\stackrel{\sim}{\sim} \\
\end{array}$ & 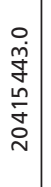 & 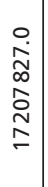 & & 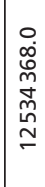 \\
\hline & 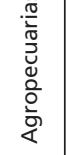 & 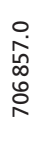 & 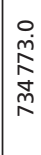 & 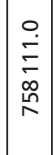 & \begin{tabular}{|l}
0 \\
$\frac{j}{\mathbf{J}}$ \\
$\frac{6}{\infty}$ \\
$\infty$
\end{tabular} & $\begin{array}{l}\stackrel{0}{0} \\
\text { ja } \\
i \\
\hat{N}\end{array}$ & $\mid \begin{array}{l}0 \\
\tilde{D} \\
\tilde{N} \\
\tilde{D} \\
i n\end{array}$ & $\mid \begin{array}{c}0 \\
\dot{0} \\
0 \\
0 \\
\tilde{Z} \\
\tilde{F}\end{array}$ & 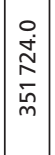 & $\begin{array}{l}0 \\
\dot{0} \\
\tilde{N} \\
\stackrel{\bar{m}}{m}\end{array}$ & 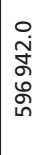 & 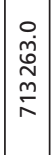 & 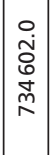 & 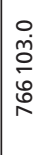 & \begin{tabular}{|l|}
$\stackrel{0}{\dot{0}}$ \\
$\hat{0}$ \\
$\hat{0}$ \\
$\hat{\infty}$ \\
$\infty$
\end{tabular} & 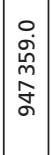 & $\begin{array}{l}0 \\
\dot{+} \\
\infty \\
\infty \\
\tilde{\infty} \\
\infty\end{array}$ & 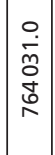 & $\mid \begin{array}{l}0 \\
\dot{d} \\
\stackrel{N}{N} \\
\dot{I} \\
\end{array}$ & 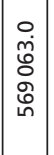 & 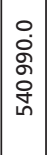 & 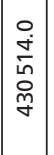 & $\begin{array}{c}0 \\
\dot{\vdots} \\
\infty \\
\infty \\
\tilde{n} \\
\end{array}$ & 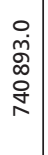 & & \begin{tabular}{|l}
0 \\
+ \\
$\dot{1}$ \\
0 \\
0 \\
0 \\
0
\end{tabular} \\
\hline & 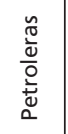 & 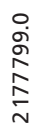 & 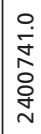 & $\mid \begin{array}{l}0 \\
0 \\
\infty \\
o \\
\infty \\
\infty \\
\sim \\
\sim\end{array}$ & 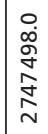 & 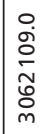 & $\mid \begin{array}{c}0 \\
\hat{i} \\
\hat{n} \\
\hat{n} \\
\tilde{n} \\
\hat{m}\end{array}$ & $\mid \begin{array}{c}0 \\
\dot{d} \\
\infty \\
\stackrel{0}{n} \\
\hat{n} \\
m\end{array}$ & 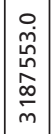 & 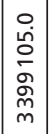 & $\begin{array}{l}0 \\
\dot{0} \\
\stackrel{1}{1} \\
\hat{n} \\
m \\
m\end{array}$ & 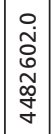 & 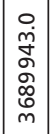 & $\mid \begin{array}{l}0 \\
\dot{o} \\
\hat{i} \\
\tilde{0} \\
0 \\
m \\
m\end{array}$ & $\mid \begin{array}{l}0 \\
0 \\
0 \\
o \\
\tilde{m} \\
\hat{m} \\
m\end{array}$ & 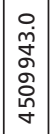 & 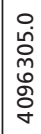 & 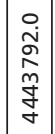 & 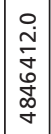 & 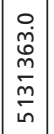 & 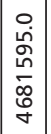 & 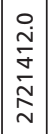 & $\left|\begin{array}{c}0 \\
\stackrel{0}{0} \\
o \\
\sim \\
o \\
\sim \\
\sim\end{array}\right|$ & $\begin{array}{l}0 \\
\dot{0} \\
\vdots \\
0 \\
\vdots \\
\sigma\end{array}$ & 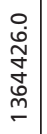 & 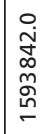 \\
\hline & $\begin{array}{l}\frac{\breve{\omega}}{\frac{\pi}{\sigma}} \\
\stackrel{\circ}{\circ}\end{array}$ & 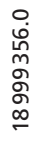 & $\begin{array}{l}\circ \\
0 \\
\infty \\
\infty \\
o \\
o \\
\stackrel{0}{0} \\
\stackrel{0}{0}\end{array}$ & 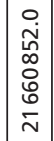 & 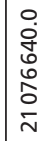 & $\begin{array}{l}\stackrel{0}{1} \\
\bar{n} \\
\tilde{m} \\
\infty \\
\tilde{N} \\
\sim\end{array}$ & $\mid \begin{array}{l}0 \\
\dot{0} \\
0 \\
\hat{L} \\
\mathbf{L} \\
\hat{N}\end{array}$ & 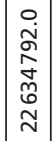 & 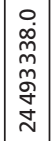 & 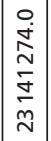 & 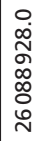 & $\mid \begin{array}{c}0 \\
\stackrel{\sim}{~} \\
\infty \\
\tilde{m} \\
\tilde{N} \\
\tilde{N}\end{array}$ & $\mid \begin{array}{c}0 \\
\dot{j} \\
\tilde{N} \\
0 \\
0 \\
\tilde{N} \\
\tilde{N}\end{array}$ & 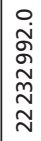 & 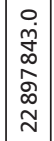 & 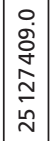 & $\begin{array}{l}0 \\
\infty \\
\infty \\
\circ \\
\infty \\
\infty \\
\infty \\
\text { స }\end{array}$ & 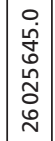 & $\mid \begin{array}{l}0 \\
\dot{j} \\
\stackrel{0}{0} \\
\infty \\
o \\
\tilde{O} \\
\stackrel{0}{N}\end{array}$ & 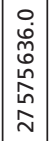 & 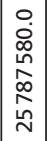 & 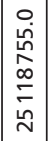 & $\left|\begin{array}{c}0 \\
\dot{\sim} \\
\text { J } \\
d \\
d \\
d \\
\sim\end{array}\right|$ & 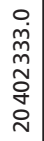 & $\begin{array}{l}0 \\
\infty \\
\infty \\
n \\
\infty \\
0 \\
\infty \\
\infty\end{array}$ & 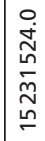 \\
\hline & & iి & ㅁ & $\begin{array}{l}3 \\
0 \\
0\end{array}$ & 离 & 尿 & $\begin{array}{l}0 \\
0 \\
0\end{array}$ & $\mid \begin{array}{l}\hat{\tilde{O}} \\
\mathbf{0}\end{array}$ & $\mid \begin{array}{l}\infty \\
\stackrel{\infty}{0} \\
\stackrel{0}{N}\end{array}$ & 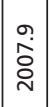 & 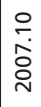 & 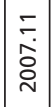 & 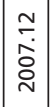 & 怘 & $\mid \begin{array}{l}0 \\
0 \\
0 \\
0 \\
0\end{array}$ & $\mid \begin{array}{c}m \\
\infty \\
\delta^{\circ}\end{array}$ & 离 & $\left|\begin{array}{l}n \\
0 \\
0 \\
0 \\
\end{array}\right|$ & \begin{tabular}{|l|}
0 \\
0 \\
0 \\
0
\end{tabular} & o & $\mid \begin{array}{l}\infty \\
\infty \\
0 \\
0 \\
\sim\end{array}$ & $\mid \begin{array}{l}0 \\
\infty \\
0 \\
0 \\
\text { N }\end{array}$ & 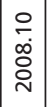 & 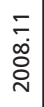 & 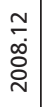 & \\
\hline
\end{tabular}


Cuadro 6. (continuación) Contribución a la evolución del comercio exterior de México

\begin{tabular}{|c|c|c|c|c|c|c|c|c|c|}
\hline & \multicolumn{4}{|c|}{ Exportaciones porcentaje } & \multicolumn{4}{|c|}{ Importaciones de bienes } & \multirow[b]{2}{*}{ Remesas } \\
\hline & Totales & Petroleras & Agropecuarias & & Totales & $\begin{array}{c}\text { Uso } \\
\text { intermedio }\end{array}$ & Consumo & Capital & \\
\hline & \multicolumn{4}{|c|}{ Porcentaje de variación } & & & & & \\
\hline 2007.1-2008.1 & 17.02 & 63.64 & 8.38 & 9.85 & 16.05 & 13.36 & 30.28 & 15.04 & -4.76 \\
\hline 2008.1-2009.1 & -31.49 & -55.28 & -9.82 & -26.81 & -30.04 & -30.12 & -44.19 & -10.32 & -11.88 \\
\hline & \multicolumn{4}{|c|}{ Participación porcentual } & & & & & \\
\hline $2007.1-2008.1$ & 100 & 42.86 & 1.83 & 47.47 & 100.00 & 60.80 & 27.72 & 11.48 & \\
\hline $2008.1-2009.1$ & 100 & -28.14 & -1.07 & -65.58 & 100.00 & -71.55 & -24.28 & -4.18 & \\
\hline
\end{tabular}

Fuente: Banxico. Indicadores de Comercio Exterior.

pos son las actividades en el mercado interno como los servicios bancarios, financieros, seguros, y los servicios de telefonía e internet. Como es natural, una proporción de la población encuentra trabajo en estas actividades, o en los que tienen vínculos directos e indirectos con el sector en cuestión. Por otra parte, los vínculos con Estados Unidos y Canadá se extienden a muchas otras áreas de negocios, desde la gran cantidad de franquicias que se observan en las calles hasta algunos negocios en el sector educativo.

Arriba vimos cómo la nueva experiencia exportadora ha generado movimientos importantes de personas hacia los municipios de creciente actividad económica, donde predomina la maquila, principalmente en la frontera norte, y hacia los industriales en otras partes del centro y norte del país. Estos fenómenos migratorios han provocado procesos de urbanización y, en especial, programas públicos para buscar satisfacer las concomitantes demandas de servicios públicos (agua, drenaje, salud y educación). Aun cuando los ingresos salariales siguen siendo bajos, tanto en relación con las necesidades de la vida moderna como con los sueldos que se perciben al otro lado de la frontera, esta parte de la población está integrada a la vida económica formal.

En varias formas, los grupos favorecidos se ven afectados por la crisis de largo plazo debido a las mayores dificultades a las que se enfrentan los jóvenes con educación básica o profesional para encontrar empleos satisfactorios. En cuanto a los efectos de la crisis, es dentro de este sector donde ha habido mayor afectación por los despidos de personal debido a la caída drástica de la demanda de exportaciones. Aunque la desocupación también afecta a las plantas automo- 
trices en Estados Unidos, en México el impacto es más severo por la inexistencia de mecanismos de protección social, como el seguro de desempleo.

Otra parte de la sociedad, sin embargo, ha sido excluida de este proceso y ha buscado salidas en la migración al extranjero, en la realización de actividades informales o sigue padeciendo situaciones de pobreza. Es sobre todo la alta proporción de esta población excluida la que justifica buscar alternativas. Un estudio sistemático y original sobre este fenómeno se encuentra en Castaingts (2000), en donde se trata, en un nivel general, bajo formas estructurales, cómo la globalización ha incorporado a ciertos países a la dinámica comercial, a la vez que ha relegado a otros y los ha dejado fuera de los circuitos principales; de manera similar, se aplica este esquema de análisis a las regiones de México.

\section{LA LIBERALIZACIÓN COMERCIAL EN MÉXICO, EL TLCAN Y LAS OPCIONES}

En general se pueden identificar dos visiones sobre los procesos de crecimiento y convergencia en relación con los procesos de liberalización comercial. La primera pone el acento en los modelos tradicionales de comercio que demuestran la eficiencia de los mercados y de la especialización comercial de cada país, bajo condiciones de libre competencia y rendimientos constantes a escala. Efectivamente, la teoría del comercio internacional considera que cuando un país lleva a cabo un proceso de apertura, los precios relativos de los bienes comerciales cambian y en consecuencia también lo hacen las rentabilidades entre los sectores. Esto implica una asignación de mayores recursos en el sector de las exportaciones y una contracción en los sectores con desventaja relativa. Este proceso de reasignación, si se mantiene el nivel de ocupación, conducirá a un aumento en la eficiencia global. Además, cuando se añade el supuesto de igual acceso a la tecnología entre países, el principio de la dotación de los factores predice que la especialización de cada país será acorde con la dotación relativa de sus factores.

La segunda visión postula la necesidad de un cambio estructural y de aprendizaje para que los agentes económicos adquieran la capacidad de asimilar conocimientos y aplicarlos en forma creativa a la solución de sus problemas dentro de un ambiente de competencia global. Esto es especialmente válido en sectores donde predominan economías de escala y se requieren mínimos de tamaño de planta para alcanzar costos de producción comparables a los internacionales; dada la naturaleza complicada del cambio tecnológico, se subraya la necesidad de llevar a cabo un esfuerzo deliberado para disponer de capacidades sociales 
(Abramovitz, 1986) o capacidades de producción y tecnológicas que permitan y faciliten la adopción de tecnologías importadas, así como su implantación en contextos particulares (Rosenberg, 1976; Fajnsylber, 1983). Aunque este enfoque no ofrece una teoría alternativa en materia de determinación de precios, considera, para efectos del estudio del desarrollo, las diferencias entre economías como muy importantes, tanto en lo que concierne a las carencias o deficiencias de sus instituciones de mercado, como en su rezago tecnológico y productivo o sus ineficiencias técnicas.

Las experiencias de crecimiento en Asia Oriental ofrecen referentes históricos para este enfoque. A partir de éstas, se identifican dos modalidades generales de transferencia de tecnología y aprendizaje de las mismas. Aunque en ambos casos la orientación comercial es exportadora, la primera recurre a la IED y la corporación multinacional, como en los casos de Singapur, Hong Kong y China; la segunda, de corte más nacionalista, se propone la creación de una base empresarial propia, como en los casos de Japón y Corea del Sur. Lo que aquí es conveniente puntualizar es que estas estrategias han requerido una u otra modalidad de intervención pública mediante combinaciones de protección y subsidios temporales, así como políticas industriales y tecnológicas. Las modalidades particulares que han asumido estas políticas han dependido de las características de cada economía, de la fase por la que ésta atraviesa, y de manera especial del contexto mundial. Ambas estrategias enfrentan su propia problemática para tener éxito (véase Amsden, 1989, para Corea del Sur; Toledo, 1998 y Tsuru, 1993, para Japón; Anguiano, 1999, para China).

Una característica común que se observa en estas intervenciones es la de promover la competitividad en sus industrias con base en ciertas secuencias de producción y comercio exterior; casi siempre se inician con producción en industrias sencillas e intensivas en trabajo (textiles, confección, madera) y avanzan hacia la promoción de otras industrias clave y con altos índices de eslabonamientos (generalmente con mayor intensidad de capital y complejas desde el punto vista tecnológico, como la del hierro y acero, transportes y químicas); pueden llegar hasta sectores de alto grado de complejidad tecnológica, dependiendo de otros factores de naturaleza económica y/o geopolítica. En concordancia con lo anterior, sus procesos de apertura también han seguido políticas secuenciales, selectivas y, en ocasiones, experimentales.

Hay varios aspectos importantes, individuales o en combinación, en estas estrategias que son objeto de debate en la bibliografía: el desempeño de las condiciones más equitativas en Asia, cuando se compara con el caso de América 
Latina [una revisión de la bibliografía se encuentra en Benabou (1997)]; la función de estados "fuertes" para el diseño e implantación de las políticas (Jones y SaKong, 1980); los factores culturales (Landes, 1998); las condiciones históricas particulares, como en el caso de la ocupación japonesa de la península coreana (Romero, 1997).

México siguió otro camino: el de la orientación exportadora bajo la integración formal y real en el espacio norteamericano. Dada la gravedad de la crisis de la deuda externa que estalló en el país a principios de los años ochenta y la fuerte inestabilidad macroeconómica que heredó el gobierno de De la Madrid, la estrategia económica que se diseñó tuvo que atender de manera prioritaria el problema de la inestabilidad macroeconómica, aunque también se planteó un programa de cambio estructural. En realidad fue hasta mediados de la década de los ochenta, cuando se inició el proceso de apertura comercial y la adhesión del país al GATT. No se establecieron condiciones para que la economía empezara a crecer sino hasta que se le dio una solución al problema del endeudamiento mediante el Plan Brady. A partir de 1989, la estrategia de desarrollo concebida por el gobierno de Salinas retomó y profundizó la ya tradicional integración de México a Estados Unidos, mediante la modalidad del TLCAN. Esta política se generalizó y la consecución de acuerdos comerciales se convirtió en el principal instrumento de política comercial, aunque no alteró el elemento fundamental de dependencia de la economía respecto del mercado estadounidense.

La estrategia mexicana tiene algunas similitudes con las modalidades seguidas por Singapur y China. Recurre a la IED para apoyar su proceso de modernización tecnológica y se sustenta en una orientación altamente exportadora. Difiere por su oposición a las políticas industriales, la ausencia de medidas complementarias a la apertura comercial, así como por las características específicasde sus perfiles de integración comercial, y por su oposición a la intervención pública analizada en la sección anterior.

Como aquí nos concentramos en las modalidades que asumieron la liberalización comercial y la integración comercial, hay que destacar que el proceso fue relativamente rápido y amplio. ${ }^{5}$ Esta estrategia alcanzó los objetivos que se

\footnotetext{
${ }^{5}$ Efectivamente, a partir de 1985 se inició la liberalización comercial. De acuerdo con Ten-Kate y De Mateo (1989), la cobertura de fracciones arancelarias sujetas a licencias de importación se redujo de $91 \%$ en junio de 1985 a 47\% en diciembre y, para finales de 1987 lo hizo aún más, hasta $25 \%$. En algunas industrias, como textiles y confección, la supresión de las licencias de importación fue más drástica que en otras, como la automotriz. En las primeras la reducción de junio a diciembre de 1985 fue de $100 \%$ a menos de $10 \%$ en un plazo menor a seis meses. En la confección
} 
habían establecido en cuanto a los flujos de inversión extranjera y la expansión exportadora, como se vio arriba. De hecho, México se consolidó como una de las economías emergentes con altas calificaciones en el mundo financiero internacional. En rigor, el acuerdo comercial con Estados Unidos y Canadá ha sido la médula de la estrategia de desarrollo económico del país. No es la ocasión para una discusión a fondo sobre el TLCAN, por lo que sólo nos referiremos a algunos de los puntos sobresalientes.

Este tratado establece no sólo una zona de libre comercio sino, tal vez de mayor importancia, una zona para el libre flujo de capitales (tanto productivos como financieros) al establecer el compromiso de dar el mejor trato posible a las inversiones extranjeras, ${ }^{6}$ y abrir a la licitación internacional (de las empresas pertenecientes a las naciones signatarias del tratado) las compras de gobierno y de empresas públicas. También establece un acuerdo sobre propiedad intelectual en los términos planteados por Estados Unidos, pero desconociendo los plazos y las modalidades diferenciadas que se habían establecido dentro del marco de la OMC para países considerados industrializados, en desarrollo y los menos desarrollados. Como todo acuerdo comercial, se incorporó una serie de mecanismos para definir la categoría de bienes originarios, la solución de controversias y otras medidas que se consideren pertinentes.

Nótese que este tratado discrimina a gran número de empresas mexicanas que se encuentran en desventaja frente a las corporaciones multinacionales de los países pertenecientes al bloque comercial. Si bien, como se analizó al final de la sección III, un grupo de corporativos mexicanos ha estado en condiciones de competir internacionalmente, gran cantidad de empresas mexicanas (así como de

se dio también un proceso rápido de reducción, esta vez en 1987. En el siguiente año se completó la eliminación del mecanismo de precios oficiales. En la revisión que recientemente han hecho de dicho proceso, Moreno-Brid, Rivas y Santamaría (2005) destacan la naturaleza unilateral de la liberalización comercial y la ausencia de políticas complementarias de promoción industrial, a excepción del programa PITEX, mediante el cual se permite la entrada libre de aranceles de insumos importados que se utilicen en la exportación.

6 “Artículo 1103. Trato de nación más favorecida. 1. Cada una de las Partes otorgará a los inversionistas de otra Parte trato no menos favorable que el que otorgue, en circunstancias similares, a los inversionistas de cualquier otra Parte o de un país que no sea Parte, en lo referente al establecimiento, adquisición, expansión, administración, conducción, operación, venta u otra disposición de inversiones. 2. Cada una de las Partes otorgará a las inversiones de inversionistas de otra Parte un trato no menos favorable que el que otorgue, en circunstancias similares, a las inversiones de inversionistas de cualquier otra Parte o de un país que no sea Parte, en lo referente al establecimiento, adquisición, expansión, administración, conducción, operación, venta u otra disposición de inversiones" (OEA, Tratado de Libre Comercio). 
potenciales inversores mexicanos) no lo están, ya que se encuentran en desventaja en su propio mercado. Además de las propias limitaciones que puedan tener sus negocios, enfrentan otras barreras como son el acceso a servicios en condiciones más favorables y baratas, como los de crédito, telefonía y telecomunicaciones. En otras palabras, el TLCAN ha vuelto los incentivos en contra de amplios sectores de productores nacionales. La discriminación también se extiende al apartado de las compras que realizan el gobierno y las empresas estatales.

En forma muy sintética es procedente hacer dos precisiones teóricas, relacionadas con las dos visiones que se acaban de exponer y con la naturaleza actual de los flujos comerciales y tecnológicos. Primero, en algunos modelos que analizan el comercio en contextos de innovación se obtienen resultados interesantes que permiten complementar o trascender los más generales basados en el principio de la ventaja comparativa. El trabajo de Grossman y Helpman (1991), al analizar la relación entre la innovación y el comercio internacional, obtiene que: $i$ ) los patrones de especialización y comercio son distintos, ya sea que se trate de la relación entre dos países "similares", es decir innovadores, o "disimilares", o bien uno con capacidades de producción e innovación y el otro sólo, o principalmente, de producción. Bajo algunos supuestos, se obtiene una versión dinámica del teorema de Heckscher-Ohlin: si el acervo de conocimientos está disponible en todo el mundo para todos los investigadores y científicos, y si éstos tienen las mismas calificaciones en todos los países innovadores, entonces el país que disponga de mayor abundancia de aquéllos se especializará en la generación de ideas y la especialización será parcial. ii) Bajo otro tipo de supuestos — principalmente que los acervos de conocimientos se circunscriben a las fronteras nacionales_- las condiciones iniciales e históricas desempeñan una función importante en la determinación de la especialización de cada país; esto es, un país que adquiera ventaja inicial en la producción de bienes que utilizan nuevas tecnologías tenderá a confirmar su especialización y liderazgo comercial en bienes de alta tecnología. Mientras tanto, el país que llegue tardíamente a la industrialización podría aprovechar las políticas públicas para compensar o revertir su desventaja tecnológica. Como aclaran los autores, en la vida real, la situación en cuanto al acceso tecnológico será intermedia entre los casos extremos que se acaban de considerar.

Segundo, en el actual contexto de globalización ha ocurrido un cambio sustancial en la organización de la producción y en la naturaleza de los flujos comerciales. Aunque una parte de éstos sigue respondiendo a las diferentes dotaciones de recursos con que cuentan los países, una proporción alta y creciente 
expresa el nuevo fenómeno denominado como relocalización de la producción, segmentación de la cadena productiva o especialización vertical. Debido a que la revolución tecnológica ha abatido los costos de transporte y comunicación, este fenómeno se ha generalizado, de tal manera que se reducen los costos de producción al aprovechar las marcadas diferencias en el costo de los factores (especialmente del trabajo con variadas calificaciones) entre países. ${ }^{7}$ En este proceso de especialización vertical, algunos países (Estados Unidos, Canadá, Japón, etcétera) se especializan en segmentos intensivos en capital y otros lo hacen en los intensivos en diferentes tipos de mano de obra (México, China, India). Desde luego, esto ha dado lugar a un creciente volumen de comercio de insumos intermedios y partes entre diferentes empresas o al interior de alguna que controla el proceso. Nuevos paradigmas, estudios y modelos se vienen elaborando para dar cuenta de estos fenómenos (Jones, 2000; Baldwin y Robert-Nicoud, 2006).

Esto se agrega a los estudios ya clásicos sobre comercio intraindustrial en los que se elaboran modelos de competencia monopolística del tipo Chamberlain y se analizan los efectos de las economías de escala como una fuente de ganancias en la especialización y el comercio internacional. Estos modelos pueden orientarse al comercio que se da principalmente entre economías de altos ingresos, mediante el cual se comercian bienes diferenciados. En ambos casos, las conclusiones son muy importantes y difieren de los modelos clásicos de la ventaja comparativa y de la dotación de los factores, basados en el teorema de Hecksher-Ohlin, en que los resultados de la especialización quedan supeditados a las condiciones iniciales o históricas y, por tanto, se abre un espacio para la política económica. Un análisis más completo de los varios tipos de comercio se encuentra en Gutiérrez (2007).

Pasamos al análisis de las propuestas. Son varias las alternativas de estrategia comercial y de crecimiento para México que se han explorado en organismos oficiales y estudios académicos. Para nuestro propósito, continuamos con una clasificación en dos grupos: el primero comprende aquellos estudios que, enfatizando lo correcto de la dirección que han tenido las reformas mexicanas, proponen medidas diversas que profundicen y/o completen estas reformas. Dentro de éstos, se encuentran estudios y propuestas de organismos internacionales como la OMC, el FMI y el Banco Mundial. Para efecto de la política comercial, se analiza uno de los últimos informes de la OMC, basado a su vez en el informe que

\footnotetext{
${ }^{7}$ Este fenómeno ha impulsado tanto la integración formal en América del Norte como la informal en Asia y el resto del mundo.
} 
México envía regularmente a esa organización (Organización de Comercio Mundial, 2008). Como se observa en este documento, después de la recesión de 2001 y 2002 el país ha mantenido la estabilidad económica y ha recuperado el crecimiento económico, aunque el crecimiento del PIB por habitante ha sido modesto y ha perdido competitividad. Por tanto, el estudio recomienda continuar con la liberalización del régimen comercial, aumentar la competencia en el mercado interno y establecer una estructura de incentivos más uniforme.

En materia de liberalización comercial, el documento reconoce que México ha reducido considerablemente sus tarifas arancelarias para bienes que provienen de los países con los cuales tiene firmados acuerdos comerciales, pero las que mantiene dentro del marco de la organización siguen siendo altas y con una estructura compleja. En realidad, el arancel promedio para productos no agropecuarios es de alrededor de $10 \%$, pero destacan las medidas antidumping que el país ha establecido y que han resultado en que, para mediados de 2007, existieran 70 medidas antidumping, principalmente para productos originarios de China y Estados Unidos. También reconoce que el país ha ido promoviendo las exportaciones mediante dos mecanismos principales, el programa de la maquiladora y el PITEX, los cuales fueron fusionados a finales de 2006 en el programa denominado IMMEX. ${ }^{8}$ Estos mecanismos consisten en otorgar concesiones fiscales y arancelarias, así como otras facilidades administrativas a empresas que cumplan con ciertos mínimos de exportación, amén del tradicional apoyo crediticio del Bancomext y otra banca de desarrollo a los exportadores.

Para promover la competitividad, México ha puesto en marcha programas de promoción sectorial (PROSECS) en varias líneas industriales, de tal manera que las compañías beneficiadas pueden importar insumos con aranceles reducidos para la producción de determinados bienes. En la práctica, éste es el mecanismo principal que se utiliza para promover la competitividad industrial. ${ }^{9}$ Un ejemplo de lo anterior lo constituye el programa ITA-Plus, mediante el cual se busca una mayor integración en los sectores de computación y telecomunicaciones. En esta cuestión, a pesar de lo limitado de los programas, la posición oficial

\footnotetext{
${ }^{8}$ Véase el Decreto para el Desarrollo de la Manufactura, la Maquiladora y la Industria de Servicios de Exportación. Los principales apoyos consisten en el reembolso automático del IVA y de los aranceles sobre importaciones que se incorporan a las exportaciones.

${ }^{9}$ En esta dirección, el gobierno mexicano redujo, de manera unilateral, los aranceles MFN para más de 6 mil fracciones arancelarias, con el propósito de reducir el costo de las materias primas para industrias que producen bienes finales; en la mayoría de los casos la reducción fue alrededor de 30\% (Organización de Comercio Mundial, 2008).
} 
de la OMC es cuestionar la racionalidad de los mismos: hasta qué punto los beneficios que se obtienen con estas medidas superan el costo fiscal que implican y las distorsiones que introducen en varias actividades económicas (Organización de Comercio Mundial, 2008, p. ix).

En cuanto al ambiente de competencia, este informe señala la persistencia de áreas en las que siguen dominando prácticas monopólicas, en especial en el sector de la energía (en donde las últimas reformas de Pemex son consideradas un avance) y en telecomunicaciones, donde destaca la posición dominante de Telmex, el precio alto que se paga por los servicios y la limitación a la participación del capital extranjero a 49\%, con la excepción de la telefonía móvil, donde se permite superar este límite, sujeto a aprobación. Finalmente, recomienda que las medidas que aplique el gobierno para promover la competitividad sean del tipo horizontal para minimizar la distorsión de los incentivos (Organización de Comercio Mundial, 2008, p. x).

Es de notar que en este reporte no se hace referencia al problema del insuficiente crecimiento de la economía mexicana durante el largo periodo desde que en 1985-1987 dio inicio la liberalización comercial y la adhesión de México al GATT. Los problemas del país siguen planteándose en términos de competitividad y se considera la continuación de las reformas económicas en los sectores de educación, energía y telecomunicaciones.

Por otra parte, se puede observar una corriente cada vez más fuerte a favor de cambios de mayor envergadura en las estrategias de desarrollo que sigue América Latina. Sin plantear medidas completamente opuestas, como sustituir al mercado o establecer barreras proteccionistas, estudios de organismos como la CEPAL (Ocampo, 1998), algunos economistas (Agenda de Desarrollo de Barcelona) y autores como Stiglitz (2007) y Stiglitz y Charlton $(2005)^{10}$ proponen redefinir la intervención del Estado para que, mediante políticas adecuadas, se impulse el crecimiento económico sostenido y la equidad. De hecho, como es ampliamente conocido, una gran cantidad de países en esta región ha introducido cambios importantes en sus estrategias; México se puede considerar una de las excepciones en el continente. El planteamiento que se hace a continuación es congruente con varios de los puntos en la Agenda de Desarrollo de Barcelona (ADB), en especial con el que establece la conveniencia de diseñar políticas adaptadas a las circunstancias y restricciones de cada país.

\footnotetext{
${ }^{10}$ Desde la perspectiva del ascenso de China en el mundo, también se puede plantear la reincorporación del Estado en la vida económica (Devlin, Estevadeordal y Rodríguez-Clare, 2006).
} 
En esta dirección, se pueden identificar varios problemas que enfrenta la industria en México:

1) Como se argumentó arriba, al otorgar "trato nacional" a los inversionistas extranjeros y a la inversión extranjera, en la práctica se ha creado un ambiente que favorece a aquellas empresas que disponen de ventajas frente a muchas empresas nacionales. También es de destacar la renuncia que hicieron los gobernantes promotores del acuerdo a la posibilidad de utilizar el instrumento de compras de gobierno para la promoción industrial selectiva en favor de ciertos segmentos de proveedores de bienes industriales y de servicios en el país, a la vez que favorecieron el desmantelamiento de un gran número de cadenas que ya existían antes de la firma del tratado.

Por tanto, se propone una variante del principio de equidad: equiparar el trato de los inversionistas en el país con el de los inversionistas extranjeros. Esto requiere que insumos generalizados como la energía, los servicios financieros y las telecomunicaciones tengan precios comparables con los del extranjero. En este sentido resultan razonables y congruentes algunas de las medidas que implanta la Secretaría de Economía, consistentes en la reducción unilateral de aranceles para gran cantidad de insumos que, por lo general, no se producen en México, y que entran en la producción nacional; el caso más destacado es el programa que se denomina ITA-Plus. De manera implícita, pareciera que para compensar la desventaja en costos, se ha mantenido una política de contención salarial. ${ }^{11}$

2) La segunda propuesta se relaciona con el problema que se ha denominado la "maquilización del país" (Rozo, 2001), debido a que la producción destinada a la exportación utiliza pocos recursos internos (principalmente mano de obra y servicios urbanos), mientras que la casi totalidad de los insumos intermedios y bienes de capital provienen del exterior. Tal es el caso no sólo de la IME sino de la mayoría de la producción exportadora en los sectores automotriz, electrónico y de telecomunicaciones. Una comparación con lo que sucede en Corea del Sur es útil: los perfiles

\footnotetext{
${ }^{11}$ A la propuesta anterior se podría responder, por la parte oficial de la OMC, que en un mundo de completo libre comercio todos los precios de los bienes y servicios comerciales se igualarían. Pero se está muy lejos de esa situación, como lo aclaran Stiglitz y Charlton (2005), y se observa con la permanencia de los subsidios agropecuarios.
} 
exportadores de los dos países son muy similares y sin embargo, en aquel país hay un alto porcentaje de contenido nacional en dichos sectores. ${ }^{12}$ El problema para México se ha vuelto muy complicado porque toma mucho tiempo alcanzar una situación en la que se desarrolle una proveeduría nacional de calidad internacional; requiere de políticas industriales y tecnológicas, bien diseñadas e implantadas a lo largo de un periodo de aprendizaje para aspirar a una situación de mayor integración de la industria con sectores exportadores.

3) La tercera propuesta se orienta a la creación de oferta nacional exportable. Una de las características que sobresale en las relaciones comerciales bajo los acuerdos de libre comercio que tiene en operación México es la baja respuesta de las exportaciones mexicanas, en comparación con la alta respuesta de las importaciones; esto evidencia una baja capacidad de oferta del país. Como estos acuerdos ofrecen ciertas ventajas, se proponen políticas para apoyar la creación de oferta por productores nacionales y extranjeros en el país que pueda exportarse a otras regiones distintas de Norteamérica. Para lograr esto se ha reconocido como útil incrementar: $i$ ) la inversión pública en áreas tradicionales de la infraestructura que hace falta para aumentar el potencial de crecimiento y reducir los costos de operación de las empresas; ii) la inversión en infraestructura moderna en materia de telecomunicaciones con un doble objetivo: enfrentar la tendencia a la desigualdad digital (the digital divide), y también generar condiciones para que los agentes operen con una eficiencia comparable a la que se tiene en otras economías; iii) promoción industrial que busque generar capacidad productiva (tanto para el mercado interno como el externo) por parte de las empresas mediante mecanismos que reduzcan o eliminen la desventaja en que ha quedado la mayoría de las empresas del país; que se continúe en la línea de los programas industriales que ha establecido el gobierno federal mediante la Secretaría de Economía, pero que, como lo plantean Moreno-Brid, Rivas y Santamaría (2005, p. 30), trasciendan el apoyo casi único del mecanismo de importación de insumos temporales, y que se apoye con "recursos financieros y humanos" que estén a la altura de los retos.

\footnotetext{
${ }^{12}$ Aunque en opinión de Se-Young el hecho es que Corea importa partes, componentes y maquinaria de alta calidad de Japón, realiza el proceso de ensamblaje y exporta a Estados Unidos. A su vez, Corea exporta componentes y partes de calidad intermedia a China, donde se ensamblan para su exportación también a Estados Unidos (Se-Young, 2006, p. 1).
} 
4) Como se vio en la sección III, el problema del bajo dinamismo de la productividad data de mucho tiempo atrás y ha continuado durante la actual fase de orientación hacia fuera. El potencial que tiene el uso de los sistemas de computación, software, redes e internet es muy considerable, y permite utilizarse en todos los ámbitos, tanto de la producción, como de la enseñanza y el familiar. Ésta es un área en la que la actividad estatal puede convertirse en una palanca para impulsar la productividad, no sólo por el mero uso de estos recursos, sino sobre todo al buscar adaptarlos a la solución de la multiplicidad de problemas que tradicionalmente han retrasado el aumento de la eficiencia. La intervención pública, mediante políticas apropiadas, es indispensable porque, como también se vio en la sección II, al tratarse de "conocimiento" se puede aprovechar su naturaleza de bien no rival y poco excluyente, pero en lo que concierne al equipo y servicios de telefonía e internet así como profesionales, éstos se vuelven rivales y excluyentes.

En el caso de México, a diferencia de otros países de América del Sur, lo anterior es más urgente por la peculiar relación comercial que se ha establecido con China. Como ha quedado de manifiesto, el ascenso de China como potencia económica ha afectado a nuestro continente de dos maneras. En forma complementaria, ha impulsado la producción y exportación de bienes primarios (el cobre de Chile, productos agropecuarios como la soya de Argentina y Brasil, el petróleo de Venezuela, etcétera); estos países se han beneficiado tanto por la tendencia al aumento de los precios de sus bienes como por la demanda de China. Por lo contrario, con México y otros países de América Central la relación es de competitividad por la similitud creciente en una gran cantidad de productos.

Finalmente, ¿qué hay acerca de la posible renegociación del TLCAN? Ha llamado la atención que, durante sus campañas, ambos precandidatos a la presidencia por el Partido Demócrata se hayan referido a la voluntad de renegociar el tratado para evitar la pérdida de puestos laborales en las manufacturas en Estados Unidos. Aun cuando el presidente Obama ha retomado la gran mayoría de sus propuestas de campaña y ha enviado varias iniciativas al Congreso, en lo referente a sus pronunciamientos sobre la modificación de la estrategia comercial de su país han surgido serias dudas de su intención de seguir adelante con su promesa. En cierta medida, el paquete de estímulo económico aprobado por el Congreso contiene algunas referencias de tinte proteccionista, y la opinión tiende a 
ser que se apegará a la tradicional política de Washington. Por el lado mexicano, a pesar de los aspectos desventajosos que se negociaron, resultaría contraproducente entrar a una renegociación en una situación de mayor debilidad que antes. Sin embargo, el hecho de la afectación a amplios sectores de productores agrícolas sigue presente y requerirá tratar el asunto de la continuación de los fuertes subsidios a los productores estadounidenses.

\section{CONCLUSIONES}

En este trabajo se ha caracterizado la crisis económica de Estados Unidos como un cierre del periodo de crecimiento dominado por las corrientes conservadoras a partir del inicio de la administración Reagan en 1982. Por la gravedad de la crisis financiera y la necesidad de que el gobierno acudiera al rescate de Wall Street, la ideología de libre mercado sufrió un serio revés. Como consecuencia, se ha abierto un nuevo periodo en el que se torna más aceptable pensar en una adecuada combinación de los mercados con regulaciones gubernamentales, lo cual se manifiesta en la llegada a la Casa Blanca y el predominio en el Congreso de Estados Unidos del Partido Demócrata. Aquí se sostiene que, al mismo tiempo, esto abre oportunidades para que México revise su anterior estrategia de crecimiento, la cual ha incumplido con sus expectativas.

En efecto, se ha caracterizado la actual situación de la economía mexicana como el resultado de una crisis de larga duración a la cual se añaden los efectos negativos de la actual crisis coyuntural. La crisis de largo plazo se manifiesta en insuficiencias en el crecimiento del ingreso, la productividad y el empleo, así como en la persistente migración de mexicanos a Estados Unidos y su incorporación a las actividades informales en nuestro país. La actual crisis afecta a toda la economía, pero la resienten también las empresas y familias vinculadas con el sector que ha obtenido mayores beneficios con la actual estrategia.

En paralelo con la crisis económica, se analizan varias características de las tecnologías de la información y la comunicación que pueden favorecer la solución de ciertos problemas de inequidad e ineficiencia en economías como la mexicana. Aun cuando, por su propia dinámica, se ha identificado que estas tecnologías pueden conducir a agrandar las desigualdades - la así llamada "brecha digital"- , también se identifican efectos positivos que pueden derivar de las propiedades de bajo grado de rivalidad y exclusión que posee la información. 
En el texto se analizan dos enfoques respecto a las reformas que se consideran necesarias para el país. El primero propone, con pequeñas variantes en la estrategia y manteniendo la estabilidad macroeconómica, continuar y profundizar la liberalización comercial, promover la competitividad en los sectores de energía y telecomunicaciones, así como establecer una estructura de incentivos más uniforme. El segundo sugiere cambios de mayor envergadura, aun cuando rechaza el proteccionismo y la sustitución del mercado por el Estado. En esta dirección, el autor propone una serie de medidas referentes a la inserción del país en la economía mundial. Dentro de éstas, establece que el TLCAN, en parte por los mecanismos que se acordaron para dar trato preferencial a la inversión extranjera, ha establecido incentivos desfavorables para la mayoría de las empresas en el país en cuestiones como las de acceso al crédito, tecnologías y mercados. Por tanto, en el texto se analizan medidas que sería necesario implantar para compensar dichos incentivos.

En una última consideración, conviene advertir sobre las serias dificultades a las que se enfrenta México para lograr diseñar e implantar políticas públicas que sean eficientes y del interés general de la población. Aunque las políticas públicas han funcionado razonablemente bien en gran número de países asiáticos, no ha sido así en América Latina ni en México, por lo que se considera más apropiado apoyarse en los instrumentos que ofrecen las TIC para construir instancias de decisión y acción pública dotadas de suficiente transparencia y capacidades de planteamiento de soluciones a los problemas en los ámbitos que corresponda. 


\section{REFERENCIAS BIBLIOGRÁFICAS}

Abramovitz, M. (1986), "Catching Up, Forging Ahead and Falling Behind", Journal of Economic History, núm. 2, pp. 385-406.

Amsden, A. H. (1989), Asia's Next Giant. South Korea and Late Industrialization, Nueva York, Oxford University Press.

Anguiano Roch, Eugenio (1999), "China en el mundo del futuro", en José Luis León (coord.), El nuevo sistema internacional: Una visión desde México, México, FCE, pp. 171-221.

Baldwin, Richard, y Fréderic Robert-Nicoud (2006), Offshoring and Globalization: What is New about the New Paradigm?, Graduate Institute of International Studies, Génova, London School of Economics, 24 de octubre.

Banco Mundial (2000), Mexico: Export Dynamics and Productivity. Analysis of Mexican Manufacturing in the 1990s, Informe núm. 19864-ME, Washington, 15 de septiembre.

— (2006), World Information and Communication for Development Report. Trends and Policies for the Information Society, Washington.

Benabou, Roland (1997), Inequality and Growth, NBER Working Paper, núm. W5658.

Bosworth, Barry (1998), "Productivity Growth in Mexico", Brooking Papers on Economic Activity. http://www.brookings.edu.

Castaingts Teillery, Juan (2000), Los sistemas comerciales y monetarios en la triada excluyente. Un punto de vista latinoamericano, México, UAM-Plaza y Valdés.

Devlin, Robert, A. Estevadeordal y A. Rodríguez-Clare (comps.) (2006), The Emergence of China. Opportunities and Challenges for Latin America and the Caribbean. Interamerican Development Bank y David Rockefeller Center for Latin American Studies, Harvard University.

Estrada López, J. L., y R. Arriaga (2004), "El comportamiento de la productividad en las manufacturas mexicanas durante la liberalización comercial y la era de los acuerdos comerciales", en L. Gutiérrez y P. García de Alba (comps.), El nuevo milenio mexicano, tomo 3, México, UAM, pp. 243-272.

- (2003), "Economic Reform and Poverty in Korea, Chile, and Mexico", en Smith, Peter H. Kotaro Horisaka y Shoji Nishijima (comps.), Asia and Latin America: in Search of a New World Order, Nueva York, Rowman \& LittleField, núm. 2, cap. 8, pp. 157-183).

Fajnzylber, F. (1983), La industrialización trunca de América Latina, México, Nueva Imagen. 
Greenspan, A. (2008), "Testimony. Committee of Government Oversight and Reform", Congreso de Estados Unidos.

Grossman, Gene, M., y E. Helpman (1991), Innovation and Growth in the Global Economy, Cambridge, Ma. MIT Press.

Gutiérrez R., Roberto (2007), "La hipótesis de Linder, la nueva teoría del comercio internacional y el comercio intraindustrial norte-sur: El caso de las economías emergentes manufactureras", México, UAM-I, tesis doctoral.

Hayek, F. A. (1944), The Road to Serfdom, The University of Chicago Press.

Hernández-Laos, E. (1985), La productividad y el desarrollo industrial en México, México, Fondo de Cultura Económica.

Hernández, Enrique, y Alenka Guzmán (2005), “Convergencia o divergencia en productividad industrial? Acumulación frente a asimilación en México y Estados Unidos”, Economía: Teoría y Práctica, núm. 22, pp. 5-42.

Homeland Security (2005), "Population Estimates", Office of Inmigration Statistics.

Jones, Charles I. (2000/1998), Introducción al crecimiento económico, Prentice-Hall.

Jones, Ronald W. (2000), Globalization and the Theory of the Input Trade, The MIT Press.

Jones, L. P., y Il. Sa-Kong (1980 a), Government, Business and Entrepreneurship in Economic Development: The Korean Case. Cambridge, Harvard University Press.

Jones, Leroy P., y Il. Sa-Kong (1980 b), Government, Business, and Entrepreneurship in Economic Development: The Korean Case. Studies in the Modernization of the Republic of Korea: 1945-1975, Harvard East Asian Monographs.

Landes, David S. (1998), The Wealth and Poverty of Nations. Why Some Are so Rich and Some Are so Poor, Nueva York, Norton.

Moreno-Brid, Juan Carlos, J. C. Rivas Valdivia, y J. Santamaría (2005), Mexico: Economic Growth, Exports and Industrial Performance after Nafta, Serie Estudios y Perspectivas, CEPAL.

Ocampo, José Antonio (1998), "Más allá del consenso de Washington: Una visión desde la CEPAL", Revista de la CEPAL, núm. 66, pp. 7-28.

Organización de Comercio Mundial (2008), Trade Policy Review, report by the Secretariat: Mexico. WT/TPR/S/195.

Pérez, Carlota (2002), Tecnological Revolutions and Financial Capital. The Dynamics of Bubbles and Goden Ages, Edward Elgar.

Piketty, Thomas, y Emmanuel Saez (2003), "Income Inequality in the United Status, 1913-1998”, Quarterly Journal of Economics 118 (1), pp. 1-39. (Información actualizada en http://elsa.berkeley.edu/-saez/.) 
Rodrik, Dani (1997), Has Globalization Gone Too Far?, Washington. Institute for International Economics.

Romer, Paul (1990), "Endogenous Technological Change”, Journal of Political Economy 98, s71-s102.

Romero, Alfredo (1998), "La nueva ética confuciana y la modernización de Corea del Sur: Una perspectiva histórico-cultural”, en J. L. Estrada, A. Escobar y O. Perea (coords.), Ética y economía. Desafios del mundo contemporáneo, México, Centro de Estudios Antonio Gramsci, UAM y Plaza y Valdés, pp. 281-316.

Rosenberg, N. (1976), Perspectives on Technology, Cambridge, Cambridge University Press.

Rozo, Carlos A. (2001), Liberalización comercial y maquilización de la economía mexicana, México, UAM-Xochimilco.

Secretaría de Desarrollo Social (Sedesol) (2002), Evolución y características de la pobreza en México en la última década del siglo XX (Comité Técnico para la Medición de la Pobreza), Mexico, , Serie Documentos de Investigación, núm. 2.

Se-Young, Ahn. (2006), "Korea's FTA Policy: Focusing on the Japan-Korea FTA and USKorea FTA", presentación.

Stiglitz, Joseph (2007), Making Globalization Work, Nueva York, W. W. Norton.

- y Andrew Charlton (2005), Fair Trade for All. How Trade Can Promote Development, Oxford University Press.

Ten-Kate, A., y F. de Mateo V. (1989), “Apertura comercial y estructura de la protección en México: Estimaciones cuantitativas de los ochenta", Comercio Exterior, núm. 39 (4), pp. 312- 329.

Toledo, Daniel (1998), "Ética, ideología y misión nacional en el sistema japonés de relaciones industriales,” en J. L. Estrada, A. Escobar y O. Perea (coords.), Ética y economía. Desafios del mundo contemporáneo, México, Centro de Estudios Antonio Gramsci, UAM y Plaza y Valdés, pp. 257-280.

Torero, Maximo y Joachim von Braun (comps.) (2006), Information and Communication Technologies for Development and Poverty Reduction. The Potential of Telecommunications, Baltimore, The John Hopkins University Press.

Tsuru, Shigeto (1993), Japan's Capitalism: Creative Defeat and Beyond, Cambridge University Press. 